Portland State University

PDXScholar

Summer 8-14-2014

\title{
Gender and Prescription Painkiller Misuse: Findings from the 2011 National Survey on Drug Use and Health
}

Robin Jo Clough

Portland State University

Follow this and additional works at: https://pdxscholar.library.pdx.edu/open_access_etds

Part of the Sociology Commons, and the Substance Abuse and Addiction Commons Let us know how access to this document benefits you.

\section{Recommended Citation}

Clough, Robin Jo, "Gender and Prescription Painkiller Misuse: Findings from the 2011 National Survey on Drug Use and Health" (2014). Dissertations and Theses. Paper 1939.

https://doi.org/10.15760/etd.1938

This Thesis is brought to you for free and open access. It has been accepted for inclusion in Dissertations and Theses by an authorized administrator of PDXScholar. Please contact us if we can make this document more accessible: pdxscholar@pdx.edu. 
Gender and Prescription Painkiller Misuse:

Findings from the 2011 National Survey on Drug Use and Health

by

Robin Jo Clough

A thesis submitted in partial fulfillment of the requirements for the degree of

Master of Science

in

Sociology

Thesis Committee:

Melissa Thompson, Chair

Matthew Carlson

Randy Blazak

Portland State University

2014 
(C) 2014 Robin Jo Clough 


\begin{abstract}
This study examines the effects of gender and social bonds on the experience of prescription painkiller misuse for men and women. The theoretical framework for the project is Travis Hirschi's social control theory (1969), and the social bond elements of attachment, commitment, involvement, and belief, which emphasizes the importance of these bonds in creating a "stake in conformity" for the individual, leading to acceptance of social norms and desistence from deviance. This theory, however, is relatively silent with regard to gender differences and was developed to examine delinquency in an all male sample of adolescents. The elements of this theory were used to further test the effects of these social bonds and add to the literature gap on the gendered experience of the misuse of prescription painkillers.
\end{abstract}

Data for this project comes from the 2011 National Survey on Drug Use and Health, an annual nationally representative, cross-sectional survey. Multivariate logistic regression analyses reveal that, being white, not being married, having less than a high school diploma, a having a job are all significant predictors of increased prescription painkiller misuse. Characteristics associated with a significant decrease in the odds of misusing prescription painkillers are being older, having a college degree, and placing importance on religious/spiritual beliefs. Multivariate logistic regression also reveals that female respondents are less likely to misuse prescription painkillers than are their male counterparts. Interaction effects are operationalized to measure the relationship between gender and the social bond elements of interest. Most of the interaction effects are not statistically significant, but some of the main effects remain significant, which indicates 
that the main effect has little impact on prescription painkiller misuse for women, but remains significant for men (marriage, education, work status). Significant interaction effects are found for gender (female) x income and gender (female) x religiosity, which indicates that for both men and women, increased income and higher levels of religiosity are significantly associated with decreased odds of prescription painkiller misuse, that the effect is stronger for women and that this difference between men and women is significant. These results provide further insight into the experiences of prescription painkiller misuse for men and women. 


\section{Acknowledgments}

I would like to thank the members of my thesis committee Dr. Melissa Thompson, Dr. Matthew Carlson, and Dr. Randy Blazak for their willing participation and helpful feedback throughout this process. I thank Dr. Thompson, my advisor and committee chair, for paying special attention to my research methods and patiently assisting me when my understanding of the intricacies of the analyses seemed elusive. Further thanks go to Drs. Carlson and Blazak for assisting with my writing and theory development, a process that seems never ending and has been crucial to all of my efforts.

I would also like to thank my fellow cohort members and others in the department, who listened, counseled, and guided me through the processes of conceptualization, implementation, and writing, providing feedback, support and, most importantly, that voice of reason when it was needed. Dylan, Cristina, Bryan, James, Amanda, Heidi, Schaylee, and Christa; I can never express to you the level of my gratitude for your encouragement and friendship over the past two years. Our cohort is truly amazing. Sonja, Bahar, and Kris: thank you for all of your help and support. I am honored to consider each of you my friend.

Most importantly, I want to thank my family for their unwavering support throughout this process. Bus and CarolAnne, Leonard, Alison, Randy, Kathleen, and Clare: without you, this entire experience would never have been possible. Thank you, everyone, for helping me to realize a life-long goal. 


\section{Table of Contents}

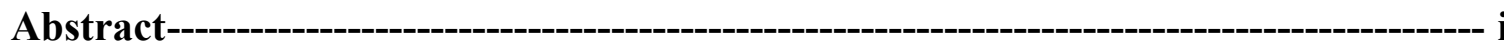

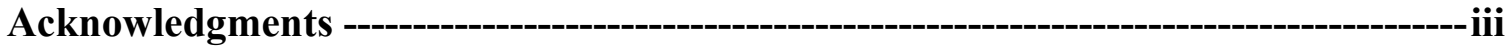

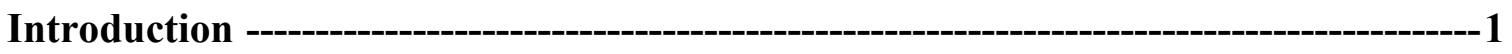

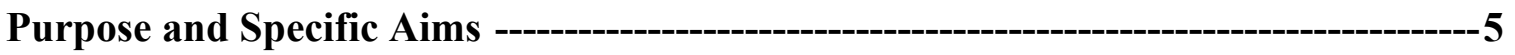

Research Questions -

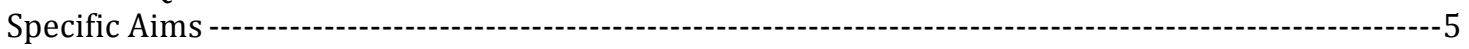

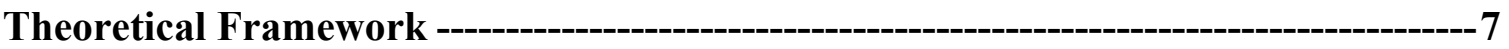

Social Control Theory ---

Gender and Social Control Theory--- 10

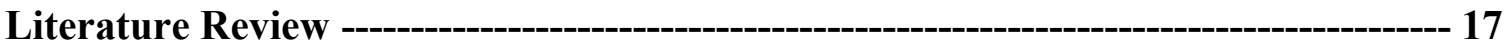

Introduction---:--- 17

Substance Misuse and Gender---ond

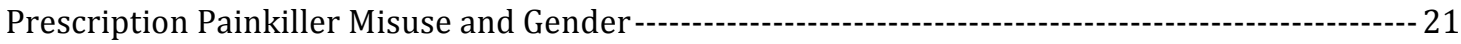

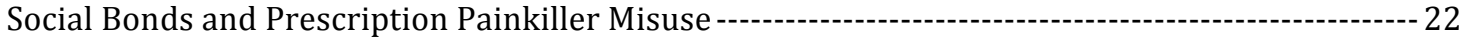

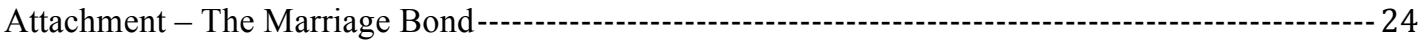

Commitment - The Education Bond--.-- 26

Involvement - The Work Bond---on 27

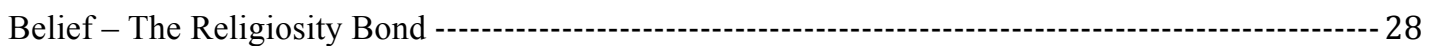

Other Factors and Prescription Painkiller Misuse-- 31

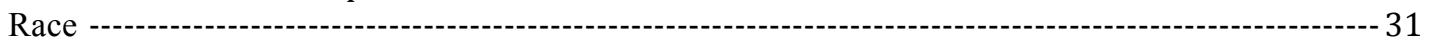

Age --o---o- 32

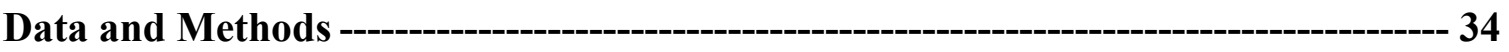

Dataset --- 34

Dependent Variable --.--.-- 34

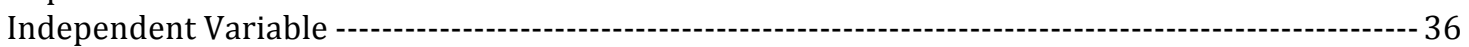

Demographic Control Variables---o- 36

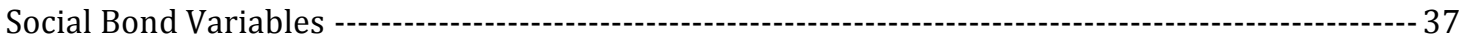

Statistical Analysis ---

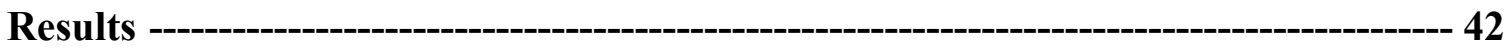

Frequencies and Univariate Analysis --- 42

Bivariate Analyses --o---o- 45

Regression Analyses -- 54

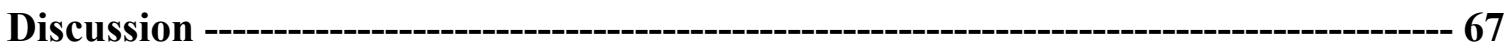

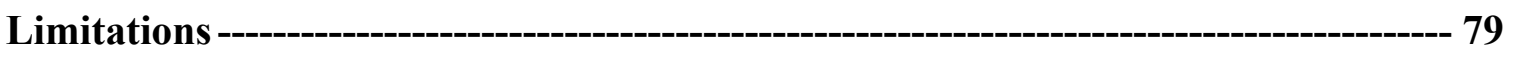

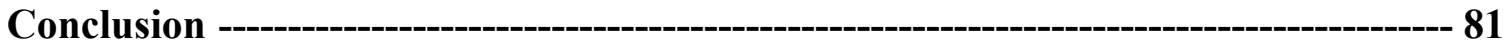

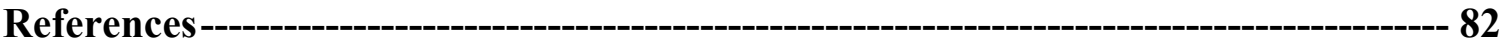




\section{List of Figures}

Figure 1: Demographics of Survey Respondents------------------------------------------- 42

Figure 2: Univariate Analysis by Misuse Status--------------------------------------- 43

Figure 3: Prescription Painkiller Misuse by Gender ---------------------------- 46

Figure 4: Prescription Painkiller Misuse by Income - Female------------------------- 49

Figure 5: Prescription Painkiller Misuse by Income - Male----------------------------- 50

Figure 6: Index of Importance of Religious Beliefs - Male---------------------------- 52

Figure 7: Index of Importance of Religious Beliefs - Female --------------------------- 53

Figure 8: Predicted Probability of Misuse - Gender x Income ------------------------- 61

Figure 9: Predicted Probability of Misuse - Gender x Religiosity ------------------ 65 


\section{List of Tables}

Table 1: Sample Characteristics by Misuse Status (18+ Years) ................................ 44

Table 2: Prescription Painkiller Misuse by Marital Status ...................................... 47

Table 3: Prescription Painkiller Misuse by Education............................................. 48

Table 4: Prescription Painkiller Misuse by Work Status............................................. 51

Table 5: Prescription Painkiller Misuse by Church Attendance................................. 54

Table 6: Logistic Regression of Prescription Painkiller Misuse ................................. 56

Table 7:_OLS of Prescription Painkiller Misuse with InteractionTerms ................... 58

Table 8:_OLS of Prescription Painkiller Misuse with Interaction Terms ................ 60

Table 9: OLS of PrescriptionPainkiller Misuse with Social Bond Interactions........ 75 


\section{Introduction}

Between 2000 and 2011 there was, what many are referring to as, "an alarming increase" in the misuse of prescription drugs (Back et al. 2010). For clarification purposes, misuse, according to the Centers for Disease Control and Prevention (CDC) and the Substance Abuse and Mental Health Services Administration (SAMHSA), is defined as using prescription drugs without a prescription, or just for the "high" they cause. With this definition in mind, between 2004 and 2011, the annual overall number of emergency room (ER) visits attributable to general drug misuse rose steadily each year, with a total increase of 52 percent, or about 844,000 visits, in that 7 year period (SAMSHA 2011). In the short term, between 2009 and 2011, ER visits involving overall prescription drug misuse increased about 400,000 visits, or 19 percent, over that 2-year period. About half of the increase in ER visits between 2004 and 2011 occurred between 2009 and 2011. In 2011, the Drug Abuse Warning Network (DAWN) estimated that about 2.5 million ER visits were the result of medical emergencies involving drug misuse. For the time period covered in the 2011 report, DAWN found that, out of 2.5 million ER visits resulting from medical emergencies involving drug misuse, 1.24 million, or 51 percent, involved nonmedical use, or misuse of pharmaceuticals.

In a 2007 report, DAWN estimated that from 2004 to 2006, ER visits related to overdoses of opioid analgesics (prescription painkillers) rose 43\% (SAMHSA 2008). By 2011, DAWN estimated that over 1.2 million ER visits involved nonmedical use of prescription medicines and over-the-counter drugs. At 46 percent, pain relievers were the most common type of drug involved in medical emergencies associated with nonmedical 
use of pharmaceuticals; narcotic pain relievers were involved in 29 percent of these emergencies. Overall, medical emergencies related to nonmedical use of pharmaceuticals increased 132 percent in the period from 2004 to 2011, with prescription painkiller misuse rising 183 percent (SAMHSA 2011). Data from a study conducted by the CDC (2013) show that in 2010, 1 in 20 people in the US (age 12 or older) reported having used prescription painkillers for nonmedical reasons within the past year. Further, data received from a nationwide Prescription Drug Monitoring Program (PDMP) indicate that enough prescription painkillers were prescribed in 2010 to medicate every American adult around-the-clock for a month (CDC 2013). Although most of these pills were prescribed for a medical purpose, many ended up in the hands of people who misused them (CDC 2013).

Previous research consistently indicates that men are more likely to abuse drugs and alcohol than women. More recent studies concur (Back et al. 2010). However, according to a July 2013 report from the Centers for Disease Control and Prevention (CDC), middle-aged women account for the fastest-growing share of overdose emergency room visits and deaths in the U.S., and their drug of choice is usually a prescription painkiller (CDC 2013). According to the CDC (2013), unintentional prescription painkiller overdose death rates have increased by 5.5 times. Deaths from prescription painkillers have reached epidemic levels in the past decade, with the number of related overdose deaths now being greater than those of deaths from heroin and cocaine combined. Nearly 15,000 people die every year of overdoses involving prescription painkillers (SAMHAS 2011). Although men are still more likely to die of 
prescription painkiller overdoses (more than 10,000 deaths in 2010), the gap between men and women appears to be closing (SAMHAS 2011). Deaths from prescription painkiller overdose among women have risen more sharply than among men; since 1999 the percentage increase in deaths was more than $400 \%$ among women compared to $265 \%$ in men (SAMHSA 2011).

Nationally, prescription painkiller overdose appears to be a serious and growing problem among women (SAMHSA 2011). For example:

- More than 5 times as many women died from prescription painkiller overdoses in 2010 as in 1999.

- Women between the ages of 25 and 54 are more likely than other age groups to go to the ER for complications arising from prescription painkiller misuse; women from 45 to 54 have the highest risk of dying from a prescription painkiller overdose.

- Non-Hispanic white and American Indian or Alaska Native women have the highest risk of dying from a prescription painkiller overdose.

- Prescription painkillers are involved in 1 in 10 suicides among women.

For every woman who dies of a prescription painkiller overdose, about 30 more will go to the ER for complications arising from prescription painkiller misuse. Nearly 18 women die every day of prescription painkiller overdose in the United States, which resulted in more than 6,600 deaths in 2010 (SAMHSA 2011).

At the state level, Oregon has the second highest rate of prescription painkiller misuse in the country (CDC 2013). Unintentional prescription drug-related death rates in Oregon have increased 2.4 times from 2000 to 2011 and deaths due to unintentional 
prescription drug overdose increased from 109 in 2000 to 289 in 2011 (CDC 2013). According to the most recent statistics, a major contributor to this problem is nonmedical use, or misuse, of prescription painkillers (SAMHSA 2011). 


\section{Purpose and Specific Aims}

The purpose of this study is to examine differences and similarities in the experience of prescription painkiller misuse for men and women. More specifically, the project will seek to understand the experience of prescription painkiller misuse through the lens of social control theory and the associated elements of the theory known as social bonds. The primary focus of the project is to determine whether predictors of prescription painkiller misuse are the same or different for men and women. Using the relevant literature and Travis Hirschi's theory of social control/social bonds as the theoretical framework guiding this study, this thesis examines the effects of gender and social bonds on prescription painkiller misuse.

\section{$\underline{\text { Research Questions }}$}

Are the predictors of prescription painkiller misuse different for men and women?

How do the different social bonds affect the experience of prescription painkiller misuse for men and women?

\section{Specific Aims}

This study will explore five specific aims associated with the previously stated research questions.

Aim 1: Examine the extent to which gender is associated with prescription painkiller misuse.

Aim 2: Examine the extent to which marital status is associated with prescription painkiller misuse for men and women. 
Aim 3: Examine the extent to which education is associated with prescription painkiller misuse for men and women education

Aim 4: Examine the extent to which employment status and income are associated with prescription painkiller misuse for men and women.

Aim 5: Examine the extent to which religiosity/spiritual belief is associated with prescription painkiller misuse for men and women. 


\section{Theoretical Framework}

\section{Social Control Theory}

Travis Hirschi's social control theory (1969) is a prominent, frequently cited theoretical framework in studies of criminology and deviance, particularly for adolescents. Its continued prominence is entrenched in a conceptual relationship between individuals and established, conventional social institutions (Booth et al. 2008). Though primarily applied to the understanding of adolescent delinquency, it can also be utilized in explanations of a variety of other aspects of deviance, in general. For example, this theory has been used in studies examining predictors of the onset of gang membership and research exploring levels of self-reported criminal activity (Thornberry, 2006; A. J. Huebner \& Betts, 2002). Social control theory is helpful in understanding many aspects of crime and deviance. By extension, given that substance misuse and dependence is categorized as deviance, social control theory can be applied to the study of drug misuse.

Social control theory suggests that humans are innately self-indulgent (Faupel et al. 2014). Social deviance, from this perspective, is assumed (Goode 2005). The focus of this theory is not to understand why people deviate from societal norms, but rather to gain understanding of why some people do conform to societal norms and laws. In other words, social control theory suggests that only conformity to social norms requires explanation. According to Hirschi's theory, the absence or presences of social bonds is the determining factor in why an individual does or does not participate in deviation from social norms. These bonds supply a "stake in conformity," where nonconformity jeopardizes existing relationships for the individual (Faupel et al. 2014). Hirschi's theory 
places the emphasis on an individual stake in conformity, where the stake equals “positively valued, reward-laden enterprises and relationships" (Goode 2005, p70).

Strong social bonds tie most people to conventional, mainstream activities, institutions, people and beliefs, while weak or broken bonds release people from regulations and laws, leading to non-normative behaviors such as drug misuse (Goode 2005). Additionally, social control theory suggests that deviance and control are matters of degree and that strong social bonds are not a guarantee of conformity. Strong social bonds will, however, make even mildly deviant behavior less likely (Faupel et al. 2014).

Hirschi (1969) identified four types of social bonds. They are:

1. Attachment: refers to emotional bonds with characteristics of conventional values and authority, or the extent to which a person is attached to others. Hirschi suggests that, as the individual becomes more attached to others, deviation from social norms is less likely (Goode 2005). According to Hirschi, key attachments and interactions are between the individuals and their parents, peers, teachers, religious leaders, and other members of a community (1969).

2. Commitment: refers to the individual's investment of time and effort into conventional lines of activity or, what Hirschi calls "the rational component in conformity" (Hirschi 1969, p20). In general, commitment is the fear of the consequences of law-breaking behavior.

3. Involvement: refers to having one's time filled with conventional activities (sports, homework, etc.). Hirschi believed that involvement in conventional activities would keep an individual's time too occupied to allow for the indulgence in deviant behavior (Goode 2005).

4. Belief: refers to a cognitive affirmation of conventional values and morality, or the existence of a common value system (Hirschi 1969). In other words, 
individuals are more likely to conform to social norms when they believe in them.

Attachment, according to Hirschi, is the representation of closeness between children and their parents or other important individuals in their lives. Examples of this closeness include the level and quality of communication between parent and child, how much time children and parents spend together, parental knowledge of friends, and levels of parental supervision and parent/child trust (Agnew, 1991; Hirschi, 1969; Miller et al. 1999). There is the expectation that a child will accept and retain more prosocial norms, such as abstinence from the use of drugs and alcohol, when stronger bonds are present between child and parent. The amount of time parents spend with children, the communication of prosocial values within the family and how each ultimately affects deviance are important components of social control theory (Wright et al. 2001).

According to Booth and colleagues (2008), commitment and involvement are a direct result of the individuals' level of attachment and subsequent internalization of prosocial norms. Commitment is an indicator of the level of acceptance that existing values and norms are well founded and valuable. It is a representation of what one may lose when participating in activities that go against accepted patterns of behavior, such as drug misuse and dependence. Involvement is derived from the idea that idle time is dangerous (Booth et al. 2008). Participation in activities such as community service and school athletics reinforces prosocial norms and lowers the likelihood that an individual will participate in activities that deviate from said norms (Hirschi 1969). When individuals are personally invested in conventional norms they are less likely to be 
involved in activities like drug misuse, which threaten their own goal achievement (Booth et al. 2008).

Beliefs legitimize the value of other social bonds (Hirschi 1969) and are an indicator of the individuals' acceptance of the rules as fair (Booth et al. 2008). Strong beliefs represent acceptance of conventional norms such as abstinence from drugs and alcohol as legitimate. Beliefs, according to Hirschi's theory, are constraining, which leads to higher levels of conformity and lower levels of deviance (Booth et al. 2008). Higher levels of prosocial attachment and commitment are suggested to lower the chances of deviant behaviors like drug misuse and dependence by increasing belief in the "moral order" (Laundra et al. 2002).

Regarding drug misuse in particular, social control theory suggests that illicit, recreational drug use can be explained by the absence of social bonds (Faupel et al. 2014; Goode 2005). From this perspective, it can be suggested that drug misuse is caused by the absence of social controls that encourage conformity (Goode 2005). The influences of parental monitoring, attachment to mother, and attachment to father are examples of social bonds that lessen the likelihood that an individual will misuse drugs (Goode 2005). In other words, according to social control theory, higher attachment to convention equals lesser likelihood of drug misuse.

\section{Gender and Social Control Theory}

The majority of previous research examining the relationship between deviance and social control has focused almost exclusively on males (Booth et al. 2008). For this reason, it is unclear whether the findings of some early studies are applicable to females. 
For example, in his original research, Hirschi's (1969) sample was limited to only young men. As such, uncertainty has arisen as to how well his theory applies to females (Alarid, Burton, \& Cullen, 2000; Cernkovich \& Giordano, 1992; Chesney-Lind \& Shelden, 2004; Dornbusch et al., 2001; A. J. Huebner \& Betts, 2002; Laundra et al., 2002), particularly since the processes of social control identified in Hirschi's research study only explain delinquency among men (Erickson et al. 2000). In other words, Hirschi's original study only tested his theory of social control on young men, making assumptions of the effects of social bonds for women problematic. For this reason, it is logical to question whether the mechanisms of social control that are experienced by men are, in fact, experienced by women in the same way.

Some data resulting from research projects that include both male and female samples suggest that there may be gender-specific mechanisms of and responses to social control that are the result of patriarchal power dynamics and gender stratification within families (Booth et al. 2008) that may lead to differences in levels of deviant behaviors such as drug misuse. In an earlier study, Hagen and colleagues (1979) found that there are what appear to be gendered mechanisms of social control. They determined that, for females, social control is more likely to be informal or protective in nature, while males are most often subjected to authoritative, formal mechanisms of social control (Hagen et al. 1979). For example, both inside and outside the home, boys are often allowed more freedom and encouraged to try new experiences than are girls. Included with this freedom are defined rules that threaten punishment if broken. On the other hand, parents and other figures of authority tend to exert strong protective controls over where girls are 
able go and how they should behave, with particular emphasis placed on polite and dignified behavior (Block 1984). In this light, men have the ability to explore and experiment with behaviors that like drug misuse, that are considered to be deviant.

Research has shown that social control factors such as parental attachment, involvement in various pro-social activities, and belief in traditional norms affect both men's and women's reports of serious deviance and risky behavior (Booth et al. 2008; Alarid et al 2000; Canter 1982; Liu \& Kaplan 1999; Smith \& Paternoster 1987). For example, there is a differentiated process of social bonding where girls, particularly in patriarchal households, have a lowered preference for risk through the acquisition of passive gender roles, placing the most importance on relational bonding (Chapple et al. 2005). This form of gendered social control is suggested to protect women from engaging in risky, deviant behaviors, such as drug misuse (Chapple et al. 2005). Other studies have shown that attachment to parents, though found to be important for both young men and young women, is a more potent protective factor against deviance for women than it is for men (Heimer \& DeCoster 1999; Huebner \& Betts 2002). This may be due, in part, to the idea that young women gain their sense of self from their (positive) relationships with their parents (Booth et al. 2008), while young men gain self-awareness and identity through their relationships with peers (Chapple et al. 2005). Further, data from other studies suggest that there is a strong negative association between involvement in community, school, and church activities and the likelihood of deviance from prosocial norms for both women and men (Booth et al. 2008; Hartman et al. 2009). In other words, increased levels of involvement correspond to decreased levels of 
deviance for both men and women.

Differing responses to social controls by young men and women are believed to emerge in response to gender role socialization rather than any innate differences between the sexes (Thorne, 1994). Data from a study by Giordano and Cernkovich (1997) suggest that relationships to families and peers may have a stronger mediating influence on young women's deviance because the results of their project indicate females tend to place a higher value on personal relationships. Consequently, young women may be more affected by the nature of these relationships than are young men (Giordano \& Cernkovich 1997). One relationship of particular interest, when considering social control theory as it pertains to adolescents, is the parent-child bond. As previously mentioned, Hirschi defines attachment as emotional bonds with characteristics of conventional values and authority, or the extent to which a person is attached to others. With this definition in mind, elements of the parent-child bond for adolescents might possibly cross over to elements of the marital bond when examining deviant behaviors such as drug misuse in older individuals.

The parent-child bond includes the elements of emotional attachment, time spent with parents, and parental monitoring. Elements of emotional attachment and time spent with another individual can be used to translate the parent-bond for adolescents into the marriage bond for older individuals. Previous research suggests that the parent-child bond may be important in reducing deviant behavior and, by extension, drug misuse. However, there are limited data regarding gender as a concept contributing to our understandings of how the parent-child bond affects said deviance (Worthen 2011). For 
older persons, only a little is known about gender differences in deviance due to marriage. There have been conflicting reports, with some studies showing close personal relationships such as marriage to have a moderating effect on drug and alcohol use (Tetrault et al. 2008; Moos \& Moos 2007; Strickland \& Smith 2013), while another found marriage to be positively associated with drug crimes for women (Alarid et al. 2000). Further, much of the available data suggest that sons and daughters have different relationships with their parents (Worthen 2011) and, as a result, there are gender differences in all elements of the parent-child bond. It might be reasonable to assume that men and women also have differing responses to being married and, as a result, gendered differences in the effect of marriage on behavior, deviant or otherwise, can also be assumed. In a 2011 study on gender differences in the parent-child bond, Meredith Worthen found that for young men, but not young women, the more positive the relationship with their parents is, the less likely they are to participate in deviant behavior. This could be due, in part, to the idea that positive relationships with parents are more normative for girls and, therefore, have a lesser impact on their participation in deviant behaviors. For this reason, it is reasonable to suggest that gender variations in the marriage bond may also contribute to significant differences in drug misuse and dependence for men and women.

In a 2008 study by Booth and colleagues, research data suggest that involvement, as it relates to community and school activities, is not significantly associated with deviance for young women, with the exception of participation in athletic endeavors, which appears to significantly reduce their likelihood of participation in deviant 
behaviors (Booth et al. 2008) such as substance misuse. For young men in the same study, the opposite, however, is true. Participation in athletics is not significantly associated with deviance for men, but community and church involvement tend to moderate their deviant behavior (Booth et al. 2008). Interestingly, the 2008 study by Booth and colleagues also found that increased levels of community involvement through multiple activities were positively correlated with deviant behavior such as drug misuse for men. In other words, for young men but not young women, participation in multiple community and school activities is associated with an increase in the likelihood of drug misuse. For young men, there appears to be a tipping point, where participation in too many activities associated with Hirschi's element of involvement can have negative consequences.

Finally, there is evidence to suggest that there are differences in how drug misuse manifests itself in the lives of men and women and that this may be due to, in part, to gendered differences in social bonds (Booth et al. 2008). For example, in a project investigating protective factors (social bonds) and resiliency by gender, Jennifer Hartman and colleagues (2009) found that women with higher levels of community and school involvement are significantly less likely to become involved in drug misuse. In the same study, involvement was not found to be a protective factor against drug misuse for men. As such, researchers in this study posit that the social bonds contributing to resiliency from drug misuse are different by gender; however, only religiosity and community involvement were significantly associated with resiliency from drug misuse for women. None of the protective factors explored were significantly associated with resiliency for 
men (Hartman et al. 2009). These gendered distinctions may, in fact, have something to do with the type and magnitude of an individual's social bonds that, as previously mentioned, may have differing effects on male and female deviant behavior (Booth et al. 2008).

The current project will use elements of social control theory to examine the effects of gender on the experience of prescription painkiller misuse. An extensive literature review has revealed that the misuse of these drugs is increasing and is a health concern going forward (Back et al. 2010; SAMHSA 2011; CDC 2013). However, only limited information is available about how gendered experiences in the misuse of prescription painkillers maybe similar or different (Back et al. 2010; Back et al. 2011). Though Hirschi's research was focused on adolescent males, this project will use the four elements of social control theory to examine adult social bonds and how these bonds affect the experience of prescription painkiller misuse for women and men. Considering the previously mentioned definitions of the individual elements from Hirschi's theory, for this research project attachment will be examined through the bond of marriage, commitment through the bond of education, involvement through the bond of work, and belief through the bond of religiosity. 


\section{Literature Review}

\section{Introduction}

Past and current research on substance abuse suggests that gender may affect the experience of alcohol and drug misuse. For example, in previous research studies on general substance misuse, socio-economic indicators, such as education and employment status are often considered to be important predictors of drug or alcohol misuse for women and men, though the effect may not be the same for both (Wilson 1978; Tetrault et al. 2008; Back et al. 2010). Additionally, demographic characteristics such as race and age have been studied extensively in relationship to substance abuse and dependence and have been shown, at times, to have differing effects on the likelihood of misusing drugs and alcohol for men and women (Barr et al. 1993; Back et al. 2010; Greenfield et al. 2010; Vogt 2010). Finally, though examined to a lesser extent, whether or not an individual is connected to community through their religiosity and/or church (Kendler et al. 1997; Haber et al. 2012) or is married or cohabiting (Alarid et al. 2000; Moos \& Moos 2007; Tetrault et al. 2008; Strickland \& Smith 2013) appear to be important indicators of misusing drugs and alcohol, however, not equally so for both men and women. For example, marriage has a buffering effect on drug and alcohol misuse for men (Tetrault et al. 2008), while women who are married tend to misuse drugs and alcohol at higher rates than women who are not (Alarid et al. 2000). Though there has been limited research on the misuse of prescription painkillers and how that misuse might be similar or different for men and women, it is possible to examine studies on other substances of abuse and 
make the argument that the misuse of prescription painkillers is likely to follow similar patterns.

\section{Substance Misuse and Gender}

Literature focusing on gender and substances of abuse, such as alcohol and nicotine, and cocaine demonstrates some differences between men and women in a number of important characteristics. Most notably, risk factors, socioeconomic status indictors, personal relationships, community involvement, race, and age have been found to be important in determining the odds of general substance abuse and dependence, and that these odds may differ by gender (Brady \& Randall 1999, Back et al. 2010). In a 1999 study, Brady and Randall found that women have greater medical, physiologic and psychological impairment earlier than men as a result of substance-use disorders. These findings suggest accelerated addiction rates for women (Brady \& Randall 1999). In other words, the time window between the onset of illicit drug use and addiction or overdose outcomes has been found to be shorter for women than for men (Greenfield et al. 2010). This phenomenon is called telescoping. Telescoping is a term used to describe an accelerated progression from the initiation of substance use to the onset of abuse and/or dependence. The phenomenon has been consistently observed in investigations of gender and substance-use disorders, with studies typically reporting an accelerated progression among women for cannabis, alcohol, and opioids, which is a class of drugs that includes prescription painkillers (Greenfield et al. 2010; Compton et al. 2007; SAMHSA 2011).

While the risk of accelerated dependence may be elevated for women, much research data suggest that men are more likely to misuse drugs and alcohol than are 
women. For example, one study found that men were 2.2 times more likely than women to misuse drugs, and 1.9 times more likely to have drug dependence issues (Compton et al. 2007). Another study found consistent gender differences in rates of substance misuse in the general population and treatment-seeking samples, with men exhibiting significantly higher rates of substance misuse, abuse, and dependence than women (Greenfield et al. 2010). Finally, in a 2010 study, Sudie Back and colleagues found that males are more likely than females $(\mathrm{OR}=1.95)$ to participate in addictive behaviors such as requesting an early refill from their doctor, using the medication for conditions other than those it was prescribed for, and having a doctor refuse to prescribe or refill the medication due to misuse concerns.

Historically, men consistently misuse drugs and alcohol at higher rates than those reported by women. However, Joseph Califano, President of the Center on Addiction and Substance Abuse at Columbia University in New York (1995), suggests that women are catching up to men in consumption of alcohol and the abuse of drugs. According to a survey conducted by the center, gender differences in the prevalence of alcohol abuse and dependence are decreasing in younger age cohorts (Kotulak 1996; Keyes et al 2008). Data from a 2008 study by Keyes and colleagues support this accumulating evidence gender differences in alcohol disorders are decreasing. The results of their study indicate consistent decreases in the odds of frequent binge drinking among males compared to among females by each successively younger cohort. Among possible explanations for these behavioral differences in age cohorts are changes in traditional behaviors, such as the proportion of women working outside the home. With the transition of more women 
into the workforce, differences in gender-based drinking norms have diminished since the 1970s (Keyes et al. 2008). Though this study focuses primarily on alcohol related behaviors, it is reasonable to assume that drug misuse by gender will follow similar patterns. Further, in a recent study, the rate of overall substance abuse and dependence among females was found to be similar to the rate among males ( $8.0 \%$ vs. $8.1 \%$, respectively) (Malbergier et al. 2012).

Finally, although substance-use disorders in general are stigmatized, Brady and Randall (1999) found that women experience more social disapproval as a result of substance misuse and that the misuse of drugs and alcohol is more stigmatized in women than men. These researchers contend that, as a result, very few women who need treatment for substance abuse actually seek it out. Further, of those women who do seek out help, the percentages are lower still when studying the success rates of substance abuse treatment for women (Brady \& Randall 1999). One explanation for these poor treatment outcomes could be that most research on substance abuse has typically been done on men. To date, most substance abuse research projects and proposed treatment models have been designed for men and are based predominantly on male norms (Kotulak 1996; Greenfield et al. 2010). Though treatment seeking and treatment outcomes are not the focus of this project, these study findings suggest that additional exploration into the differences and similarities of prescription painkiller misuse by gender may be warranted. 


\section{Prescription Painkiller Misuse and Gender}

In a research study performed in 1995, the Center on Addiction and Substance Abuse at Columbia University in New York found that the percentage of women who abuse prescription drugs appears to be running neck and neck with men; 3.7 percent for females compared with 3.9 percent for men (Kotulak 1996). However, until recently the role of gender with specific regard to prescription painkiller misuse has received little attention. Some conflicting data regarding the misuse of prescription painkillers and gender has been put forward. For example, one report based on two large epidemiological surveys found that women engage in the misuse of prescription painkillers more often than men (Simoni-Wastila et al. 2004). In contrast, another report based on the 2007 National Survey on Drug Use and Health suggests that men misuse prescription painkillers at higher rates than women (Tetrault et al. 2008), while an additional report based on the substance abuse patterns of adolescents in Brazil suggests that, globally, overall substance abuse rates and the misuse of prescription painkillers, in particular, are similar for males and females (Malbergier et al. 2012).

Important gender differences have been found in prevalence and risk factors for abuse of prescription painkillers. For example, recent research has shown women to be more likely to become addicted to prescription painkillers than men, which suggests that they may also be susceptible to increased abuse of these drugs (McCabe et al. 2008; Lofwall et al. 2012; McNelis 2012). This phenomenon, known as telescoping for women, was defined and briefly discussed in a previous section. In addition, differences have also been identified in how and from whom men and women obtain prescription 
painkillers. Men are more likely to obtain prescription pain medication from their peers, while women were more likely to obtain said medication from a doctor or familial source (McCabe et al. 2008; Back et al. 2009). A recent report by the CDC (2013) confirms these findings, stating that the misuse of prescription painkillers and associated behaviors manifest differently for women and men. For example:

- Women are more likely to have chronic pain, be prescribed prescription painkillers, be given higher doses, and use them for longer time periods than men.

- Women may be more likely than men to engage in "doctor shopping" (obtaining prescriptions from multiple prescribers).

These data suggest that prescription painkiller misuse may be part of a larger cluster of problem behaviors, which also includes acquiring prescription pain medication from peers (CDC 2013). A separate study investigating unintentional pharmaceutical overdose fatalities $(\mathrm{N}=295)$ found that prescription painkillers were taken by $93.2 \%$ of decedents, but that less than half had a prescription for the use of these drugs (Hall et al. 2008).

Based on this research, I hypothesize that women are less likely to misuse prescription painkillers than are men.

\section{$\underline{\text { Social Bonds and Prescription Painkiller Misuse }}$}

In current literature on substance misuse few, if any, studies can be found with the explicit intention of exploring social bonds, such as religiosity or marriage, and how these bonds impact the experience of substance misuse and dependence or if there are differing or similar experiences based on gender. Even less can be found on these social bonds with regard to their effect on the misuse of prescription painkillers for women and 
men. Because Hirschi's theory is based on studies involving adolescent males and desistance from delinquency, for this research project the elements of attachment, commitment, involvement, and belief will be examined through the bonds of marriage, education, work, and religiosity. In using these bonds in this project, it is possible to extend social control theory to the experiences of adults, with the inclusion of gender in order to examine similarities and differences in the experience of prescription painkiller misuse for women and men.

Studies of general substance abuse and alcohol abuse and dependence often examine social environments and familial ties as they pertain to the individual and coinciding experiences of substance abuse and dependence (Moos \& Moos 2007; Strickland \& Smith 2013). Whether or not the individual is married or partnered is also a prominent variable in some of these studies (Alarid et al. 2000; Tetrault et al. 2008). Additionally, educational attainment and school attendance are often included in research exploring general substance abuse, particularly in studies on alcohol abuse and dependence (Tetrault et al. 2008; Baker et al. 2011). Further, work and past-year misuse of drugs and alcohol have typically been reported for men. Some recent study findings suggest that the same may be true for women (Tetrault et al. 2008; Back et al. 2010). Finally, while spirituality/religion is often mentioned in articles and reports pertaining to the treatment of drug and alcohol addiction through 12-step recovery programs, studies that provide understanding about how spirituality or religiosity may or may not affect the experience of substance misuse, specifically the misuse of prescription painkillers, are limited. Most of the available studies attempting to understand measures of religiosity 
and substance misuse are focused primarily on alcohol abuse and dependence, using a wide variety of religiosity dimensions to make their point (Kendler et al. 1997; Patock et al. 1998; Michalak et al. 2007; Haber et al. 2012).

It could be argued that, due to the scarcity of literature on the misuse of prescription painkillers and because addiction to alcohol and drugs and the experience of misusing them is considered to be similar (Freed 1973; Skinner 1982; McLellan et al. 1994), an examination of the literature on marriage, education, work, and religiosity, and how each affects alcohol use, in addition to general substance misuse, is appropriate. The following is a discussion of said literature.

\section{Attachment - The Marriage Bond}

The social environment plays a critical role in determining the likelihood that an individual will use drugs or will develop a drug use disorder (Strickland \& Smith 2013). Strong familial ties, such as being in a marriage or intimate partnership, appear to be associated with lower rates of drug abuse (Strickland \& Smith 2013) and predict better alcohol-related outcomes (Moos \& Moos 2007). Additionally, for both women and men, an inverse relationship was seen between being married and past-year non-medical use of prescription painkillers (Tetrault et al. 2008). In other words, according to the results of this study, both men and women are less likely to misuse these drugs if married. Interestingly, a study examining gender and drug use and drug crimes found that one of the strongest predictors for increased deviance (drug use/crime) in women, but not men, is being married or partnered (cohabiting) (Alarid et al. 2000). This finding is not 
unusual in criminological studies of gender and offending. For example, research has indicated that for most women who participate in drug misuse, the pool of available steady partners tends to be limited to others who misuse drugs (Thompson \& Petrovic 2009). Further, though based primarily based on a male perspective, one theory of crime suggests that marriage is, in fact, a significant predictor of the inhibition of criminal behavior for men (Sampson \& Laub 2003). The same, however, is not true for women. In their book entitled Crime in the Making: Pathways and Turning Points Through Life, Sampson and Laub (2003) make note of gender differences in criminal behaviors. They wrote,

Given the crime differences between men and women, it is almost invariably the case that men marry "up" and women "down" when it comes to exposure to violence and crime.... Indeed feminists are justified, by this logic, in recoiling at arguments about "good marriage" effects. Good for whom, we must ask. Yet given the gendered nature of Sampson and Laub's sample along with the historical context, we cannot help but focus here on male outcomes. We look to other scholars to uncover the role of marriage, if any, in the offending careers of women (pp. 45-46).

Though this theory is mainly addressing the effect of marriage on the inhibition of criminal activities for men, the authors' suggestion that marriage for women may not have the same effect on their criminal behavior, and by extension drug misuse, could be interesting to consider when examining prescription painkiller misuse, specifically, and how men and women who are married/partnered might experience it differently. Attachment, as previously defined according to social control theory, refers to 
emotional bonds with characteristics of conventional values and authority, or the extent to which a person is attached to others, such as parents, peers, and teachers for adolescents. For this project, attachment will be considered in regards to marriage or intimate partners for the adult study population.

Based on this research, I hypothesize that men who are married are less likely to misuse prescription painkillers than are men and women who are not married. I hypothesize further that women who are married are more likely to misuse prescription painkillers than are men and women who are not married.

Commitment - The Education Bond

Some recent literature on predictors of drug misuse suggests significant associations between formal educational attainment and individual health outcomes and risks such as mortality and drug abuse (Baker et al. 2011). Studies of this nature consistently conclude that more highly educated individuals are healthier and are living longer. This association is so widespread that the general conclusion has become that education has an enduring influence on health outcomes such as the misuse of narcotics (Baker et al. 2011). A previous study by Baker and colleagues points to ways in which education influences individuals. For example, aside from the obvious benefits of material resources and social status, education can change self-image perceptions of the individual in relation to others. Each of these mechanisms has been used by past research to explain this education effect on overall health, which includes discussions of drug abuse and dependence (Baker et al. 2011). 
In a study examining gender and the misuse of prescription painkillers, Tetrault and colleagues (2008) found that among the characteristics associated with past-year misuse of prescription painkillers for women, is having a highest level of education completed between 9th and 11th grades, or less than high school graduation. Further, for men but not women, completing high school to the 12th grade was associated with pastyear misuse of prescription painkillers (Tetrault et al. 2008).

As previously stated, according to Hirschi's social control theory, commitment refers to the individual's investment of time and effort into conventional lines of activity or "the rational component in conformity." For the current project, this element will be represented by the respondents' level of education.

Based on this research, I hypothesize that men and women with higher levels of education are less likely to misuse prescription painkillers than are men and women with lower levels of education.

Involvement - The Work Bond

Discussions of employment as it pertains to the incidence of drug misuse are limited and tend to be part of the larger discussion of general substance abuse. One study that was particularly focused on gender and the misuse of prescription painkillers found that for women but not men, being employed was associated with past-year misuse of prescription painkillers (Tetrault et al. 2008). The general discussion regarding this phenomenon suggests that this increase in misuse for working women might have something to do with increased contact with colleagues and coworkers who misuse drugs 
(Tetrault et al. 2008). Results from a different study by Sudie Back and colleagues (2010) show that being male and employed were significantly and positively associated with any lifetime misuse of prescription painkillers, which is consistent with other studies of general substance abuse (Brady \& Randall 1999; Compton et al. 2000).

According to Hirschi's theory, involvement refers to having one's time filled with conventional activities that keep an individual's time too occupied to allow for the indulgence in deviant behavior. For adolescents, such activities would be participation in sports or doing homework. For this project, work status and income represent the involvement element of social control theory. Income is incorporated as an indicator of time spent at work, where higher income suggests increased work hours.

Based on this theory, I hypothesize that men and women with higher income are less likely to misuse prescription painkillers than are men and women with lower income. I hypothesize further that men and women who are working are less likely to misuse prescription painkillers than are men and women who are not working.

\section{Belief - The Religiosity Bond}

As previously stated, available literature on spirituality/religiosity and alcohol and substance abuse use wide variety of spirituality/religiosity dimensions, differing in definition by study. For example, Kendler and colleagues (1997) examined personal devotion, personal conservatism, institutional conservatism in a study on religiosity and substance abuse. The study results showed that all three are of these dimensions are strongly tied to family relationships and environment and, when measured together, give 
a good representation of general religiosity (Kendler et al. 1997). Further, these researchers found that this religiosity is significantly and inversely related to general substance use and is one of the most important familial-environmental factors affecting substance misuse and dependence (Kendler et al. 1997). Finally, all three of the religiosity dimensions in this study are significantly and inversely related to levels of alcohol consumption and lifetime alcohol use disorders. Personal devotion is most strongly and negatively associated to drug and alcohol use, while personal devotion and the conservative nature of the church are most strongly and negatively associated with lifetime history of alcoholism and addiction (Kendler et al. 1997).

A separate study focusing on differences in alcohol consumption and problem drinking measured religiosity through the dimensions of motivation-devotion, religious attendance, and existential well-being (Haber et al. 2012). Results from this study found that religiosity/spirituality variables were independent influences on alcohol abuse, not mediators/moderators. Further, all three dimensions were strongly associated with abstinence from alcohol and that a lower prevalence of problem drinking was found for those church affiliations having rules against all alcohol use. Churches in this study having the fewest members who are problem drinkers tended to self-describe as "biblical, conservative, or fundamental" (p41). In other words, church denomination and the associated tenets around alcohol consumption matter. Similar studies found that church denomination had a direct effect on an individuals' level of alcohol consumption. In one such study, religious preference is significantly associated with all drinking behaviors, with Christian/no denomination, Baptist and Catholic significantly associated with 
heavier drinking (Michalak et al. 2007). Yet another project that focused on denomination (Catholic vs. Protestant vs. No Religion) found individuals claiming no religion participated in significantly more alcohol use than did all other study participants (Patock et al. 1998). This study also found that male Catholics have significantly higher alcohol use than female Catholics, while female Catholics have the same use as Protestants as a whole (Patock et al. 1998).

In all of these studies, religiosity/spirituality, with dimensions defined and operationalized for each differently, is significantly associated with decreased alcohol consumption. Because, as previously stated, alcohol abuse and the misuse of drugs are often used interchangeably in discussions of general substance abuse, it is reasonable to assume that religiosity will have some effect on the experience of prescription opiate misuse.

Because Hirschi refers to the element belief in social control theory as a cognitive affirmation of conventional values and morality, or the existence of a common value system, religiosity will be utilized as a representation of this element of social control theory for this project. It might be important to mention that, because of the relevance of church denomination in drinking behavior of church members, religiosity might also be associated with the attachment element.

Based on this research, I hypothesize that men and women with higher levels of religiosity are less likely to misuse prescription painkillers than are men and women with lower levels of religiosity. 


\section{Other Factors and Prescription Painkiller Misuse}

Not part of social control theory as a contribution to the social bond discussion, but still important to our understanding of the gendered experience of prescription painkiller misuse, are specific demographic control variables. For this research project, demographic control variables of race and age will be utilized.

\section{$\underline{\text { Race }}$}

General sociological and criminological discussions of race as it relates to drug misuse are consistent. White men and women are more likely to participate in drug misuse and drug crimes than are non-white men and women (Alarid et al. 2000; Compton et al. 2000). Specific to prescription painkillers, however, for men but not women, white race or Hispanic ethnicity are associated with past-year misuse (Tetrault et al. 2008).

In a study examining the effects of race on the drug use patterns of young adults, Compton and colleagues (2000) found that, among self-reporting prescription painkiller misusers, blacks misuse prescription painkillers at rates that are lower than those reported by whites (40\% and $66 \%$, respectively). This gap is even wider between women, with $39 \%$ of black women reporting the misuse of prescription painkillers compared to $73 \%$ of white women (Compton et al. 2000).

An early study regarding race and drug abuse includes consideration of the relationship between class polarization and gender (Wilson 1978) as the key to which individuals are more likely to misuse drugs. According to William Wilson (1978), in contrast to black males with lower socio-economic status, middle-class black men have benefitted from civil rights legislation and affirmative action programs (Barr et al. 1993). This differentiation and displacement may lead poor black men to alternative ways of 
coping, which is often linked to higher rates of criminal activity, including drug misuse (Barr et al. 1993). Additionally, a recent study includes age and socio-economic status as predictors of drug abuse (Vogt 2010). These studies expand Wilson's earlier research, indicating that age and work, along with economic conditions, help to better explain most of the relationship between race and drug and alcohol misuse (Vogt 2010).

Age

As is the case for race and drug misuse, research data on age and drug misuse tends to be consistent. For example, in one study that pulled data from the 2002 to 2004 NSDUHs found that, in adolescence, girls aged 12 to 17 years of age had higher rates of misuse than boys, but that men aged 18 to 25 years had higher rates of misuse than women (Greenfield et al. 2010). Two relatively recent studies, looking specifically at predictors of prescription painkiller misuse, found that being less than 35 years old is a significant predictor non-medical use of prescription painkillers for both women and men (Back et al. 2010; Tetrault et al. 2008). Additionally, having the first illicit drug experience at younger than 20 years of age is associated with past year misuse of prescription painkillers for both women and men. In contrast, one study examining gender and the experience of drug use and drug crime found that as age increases, involvement in drug crimes also increases (Alarid et al. 2000). The data resulting from this study contradict popular thought that increased age leads to an "aging out" from deviant behaviors, such as drug misuse. One possible explanation for this contradiction could be that the focus of the study was drug crime activity that included incidences of drug misuse as part of the definition of criminal activity, thereby suggesting an increase 
in age is correlated to an increase in drug misuse by virtue of the drug crime definition.

The misuse of prescription painkillers is an increasing problem and has become a serious health concern (Back et al. 2010; SAMHSA 2011; CDC 2013). Only limited information is available about how gender affects the misuse of prescription painkillers and how this experience maybe similar or different for men and women (Back et al. 2010; Back et al. 2011). This project will use Travis Hirschi's social control theory examine adult social bonds and how they affect the experience of prescription painkiller misuse for women and men. Because the majority of current literature on prescription painkiller misuse is based on the research and data analyses of clinicians looking to inform existing prevention and treatment programs, the exploration of social processes and application of sociological theory is all but non-existent in any of the available analyses. Through a social control theoretical lens, this project will seek to illuminate the social bonds that are associated with prescription painkiller misuse and attempt to contribute to the expansion of our understanding of the problem through the exploration of differences and similarities in prescription painkiller misuse by gender. 


\section{Data and Methods}

\section{Dataset}

For the purposes of this project, secondary survey data from the 2011 National Survey on Drug Use and Health (NSDUH) were used. The NSDUH is an annual crosssectional survey sponsored by the Substance Abuse and Mental Health Services Administration with the purpose of measuring the prevalence and correlates of drug use and provides information about the use of illicit drugs, alcohol, and tobacco in the U.S. The inclusion criteria for participating in the NSDUH is anyone within the civilian, noninstitutionalized population of the United States (including civilians living on military bases) who are 12 years of age or older. The sampling methodology employed for the NSDUH is derived from a 50-State design with an independent, multistage area probability sample for each of the 50 States and the District of Columbia. In 2011, there was a target sample size of 70,000. 70,109 surveys were attempted, having a total of 58,397 being completed, with a response rate of $86.98 \%$. Each respondent in 2011 received $\$ 30$ for his or her participation in the survey.

\section{Dependent Variable}

In order to utilize a comprehensive measure of prescription painkiller misuse as the dependent variable for this project, prior to performing analysis with the NSDUH data recoding of some of the relevant survey questions was necessary. The following four questions regarding prescription painkiller misuse were recoded into the study dependent variable: 
- Have you ever, even once, used Darvocet, Darvon, or Tylenol with codeine that was not prescribed for you or that you took only for the experience or feeling it caused?

- Have you ever, even once, used Percocet, Percodan, or Tylox that was not prescribed for you or that you took only for the experience or feeling it caused?

- Have you ever, even once, used Vicodin, Lortab, or Lorcet that was not prescribed for you or that you took only for the experience or feeling it caused?

- Have you ever, even once, used any of these pain relievers when they were not prescribed for you or that you took only for the experience or feeling they caused?

The last question of the four refers to an exhaustive list of prescription painkillers that are less well known than those mentioned in the first three questions.

The study dependent variable was recoded as the binary variable PAINKILLER18PLUS (age coding explained in independent variable section), indicating the misuse or non-misuse of any prescription painkiller, with "misusers" coded as 1 and "non-misusers" coded as 0 (the reference category). All respondents indicating that they have misused prescription painkillers by answering yes to any one of these questions are included in the analysis. 


\section{Independent Variable}

Concept: Gender.

In the $2011 \mathrm{NSDUH}$, the SEX variable refers specifically to biological sex and is coded as: $1=$ male, 2 = female. SEX was recoded into a dummy variable called FEMALE, where "female" is coded as 1 and "not female" is coded as 0.

\section{Demographic Control Variables}

Concept: Race.

The variable for race in the 2011 NSDUH is called NEWRACE2 and is coded as: $1=$ Non-Hispanic White, 2 = Non-Hispanic Black/African American, 3 = Non-Hispanic Native American/Alaskan Native, 4 = Non-Hispanic Native Hawaiian Islander/Other Pacific Islander, 5 = Non-Hispanic Asian, $6=$ Non-Hispanic more than one race, $7=$ Hispanic. The NEWRACE2 variable was recoded into the following 4 dummy variables: WHITE, where Non-Hispanic White is recoded as "white" and given a value of 1, with the reference category of "not white" coded as 0; BLACK, where Non-Hispanic Black is recoded as "black" and given a value of 1, with the reference category of "not black" coded as 0 ; HISPANIC, where Hispanic is recoded with a value of 1 , with the reference category of "not Hispanic" is coded as 0; OTHER where Non-Hispanic Native American/Alaskan Native, Non-Hispanic Native Hawaiian Islander/Other Pacific Islander, Non-Hispanic Asian, and Non-Hispanic more than one race is recoded as "other race" and given a value of 1 , with the reference category of "not other race" coded as 0 . For the purposes of this project, WHITE was used as the reference category because, for 
this control variable, it is appropriate for the reference category to be the most common or largest category.

Concept: Age.

In the $2011 \mathrm{NSDUH}$, the age (AGE2) variable is an ordinal variable coded with the following categories: 12 years, 13 years, 14 years, 15 years, 16 years, 17 years, 18 years, 19 years, 20 years, 21 years, 22 or 23 years old, 24 or 25 years old, 26-29 years old, 30-34 years old, 35-49 years old 50-64 years old, and 65+ years old. For this study, the age variable was recoded to completely exclude "12-17 year olds," but keeping all other categories the same. The recoded age variable has the following categories: 18 years, 19 years, 20 years, 21 years, 22 or 23 years old, 24 or 25 years old, 26-29 years old, 30-34 years old, 35-49 years old 50-64 years old, and 65+ years old. The justification for these recoding criteria is that, for many of the variables of interest (marital status, spiritual belief, church attendance), this portion of the study population are not asked the questions.

\section{Social Bond Variables}

Concept: Marital status.

The marital status variable (IRMARIT) in the 2011 NSDUH is coded as: $1=$ Married, $2=$ Widowed, $3=$ Divorced $/$ separated, $4=$ Never married. IRMARIT was recoded into the three new binary variables called MARRIED, where 'married is coded as 1 and all others are coded 0, NOTMARRIED, where 'widowed' and 'divorced/separated' are coded 1 and all others as 0, and NEVERMARRIED, where 'never married' is given a value of 1 and all others are coded 0 . MARRIED is the 
reference category for this concept. The use of binary variables is appropriate in this situation because including these categorical variables as continuous variables assumes that a one unit change in any of the variables results in the same effect on the outcome, which may not be the case. For example, using marital status as a continuous variable assumes that going from [1) married] to [2) widowed] has the same marginal effect as going from [3) divorced/separated] to [4) never married]. Further, 'married' is best suited to be the reference category because it represents a theoretically driven social bond, to which all other marital statuses will be compared.

Concept: Socio-economic status (3 indicators).

Indicator 1: Family income

In the $2011 \mathrm{NSDUH}$, the family income (INCOME) variable is coded as: $1=$ Less than $\$ 20,000,2=\$ 20,000-\$ 49,999,3=\$ 50,000-\$ 74,999,4=\$ 75,000$ or more. The INCOME variable for this project was not recoded and remains as an ordinal variable.

Indicator 2: Education

The education variable (EDUCCAT2) in the 2011 NSDUH is coded as: $1=$ Less than high school, 2 = High school graduate, $3=$ Some college, $4=$ College graduate, $5=$ 12 to 17 year olds. The EDUCCAT2 variable was recoded into the following four binary variables: LTHS, where 'less than high school' is given a value of 1, with all others coded as 0 ; HS, where 'high school graduate' is coded with a value of 1 , with all others coded as 0 ; SC, where 'some college' given a value of 1 , and all others are coded as 0 ; CG where 'college graduate' is given a value of 1 , with all others coded as 0 . For the purposes of this project, HS is the reference category. The use of binary variables is appropriate in this situation because, similar to the variable for marital status, including 
these categorical variables as continuous variables assumes that a one unit change in any of the variables results in the same effect on the outcome, which may not be the case. Category 5, "12 to 17 year olds," has been excluded through earlier recoding of the age variable.

Indicator 3: Work Status (past week) In the 2011 NSDUH, the work status (JBSTATR2) variable is coded as: $1=$ Has fulltime job-worked, 2 = has part-time job-worked, 3 = has job/volunteer position-did not work, $4=$ Unemployed, $5=$ Disabled, $6=$ Keeps house-fulltime, $7=$ In school $/$ training, 8 $=$ Retired, $9=$ No job-other reason. JBSTAT2 was recoded into a binary variable (WORK) with 1, 2, and 3 above coded as "working" (value=1) and 4-9 above coded as "not working" (value=0).

Concept: Spirituality/Religiosity (2 indicators). Indicator 1: Religiosity Index In order to utilize a comprehensive measure of spirituality/religiosity as a social bond variable for this project, prior to performing analysis with the NSDUH data a religiosity index was created. The following three statements regarding the importance of respondents' spiritual beliefs were recoded into the religiosity index.

My religious beliefs are very important to me. My religious beliefs influence my decisions. It is important that my friends share my religious beliefs.

The response categories for each of these statements are $1=$ Strongly disagree, 2 $=$ Disagree, $3=$ Agree, and $4=$ Strongly agree. Prior to creating the index, a reliability 
test is run to determine the appropriateness of combining these variables. Cronbach's alpha is a coefficient of internal consistency and is measured as follows:

$$
\begin{aligned}
& \text { Excellent }=\alpha \geq 0.9 \\
& \text { Good }=0.7 \leq \alpha<0.9 \\
& \text { Acceptable }=0.6 \leq \alpha<0.7 \\
& \text { Poor }=0.5 \leq \alpha<0.6 \\
& \text { Unacceptable }=\alpha<0.5
\end{aligned}
$$

The Cronbach's alpha for this combination of variables is .834 , which indicates that the combination is appropriate. After recoding, the index scale ranges from 3 to 12, with 12 being the highest level of religiosity possible for this index, where the respondents' beliefs are very important, and 3 being the lowest, where religious beliefs are not important.

Indicator 2: Church Service Attendance The variable for church attendance in the 2011 NSDUH is called SNRLGSVC and the associated question is worded:

During the past 12 months, how many times did you attend religious services (do not include special occasions such as weddings, funerals, or other special events)?

The response categories for this question are $1=0$ times, $2=1$ to 2 times, $3=3$ to 5 times, $4=6$ to 24 times, $5=25$ to 52 times, and $6=$ More than 52 times. The SNRLGSVC variable was recoded into the following a binary variables: CHSVCNEVER, which includes response category 1; CHSVCRARLEY, which includes response categories 2 and 3; CHSVCOFTEN, which includes response categories 4 and 5; CHSVCFREQ, which includes response category 6. The reference category for this 
concept is CHSVCNEVER. Similar to the marital status and education variables, the use of binary variables is appropriate in this situation because including these categorical variables as continuous variables assumes that a one unit change in any of the variables results in the same effect on the outcome, which is likely not be the case. The most common, or largest category is CHSVCNEVER, which was used as the reference category.

\section{Statistical Analysis}

Using SPSS, Version 21, a frequency distribution of respondents reporting the misuse of prescription painkillers and a univariate analysis of the newly recoded dependent variable, PAINKILLER18PLUS, were run. Using a gender-stratified version of the dependent variable, crosstabs were then performed between the dependent variable and all variables that were determined to be of interest following a thorough literature review. Because the dependent variable is binary, this project has employed multivariate logistic regression analyses with interaction effects between gender (female) and all of the social bond variables. This approach addresses each of the specific aims while modeling the effects of gender on prescription painkiller misuse. 


\section{Results}

\section{Frequencies and Univariate Analysis}

Figure 1 presents a breakdown of demographic information for the population of interest, after eliminating respondents between the ages of 12 and 17 years old. For the study sample population, 18 years of age and older, about $47 \%$ are male, while nearly $53 \%$ of respondents are female. Further, $63 \%$ of respondents in the study sample are white, with nearly $13 \%$ being black, and about $16 \%$ identifying as Hispanic. The majority of the sample population reports having never been married (53\%), while 35\% are married and $12 \%$ are not married. Additionally, $49 \%$ of respondents are $18-25$ years old, while nearly $20 \%$ are between the ages of 35 and 49 years old. Another $17 \%$ of the sample population is 50 years of age or older, with the fewest number of respondents

\section{Figure 1: Demographics of Survey Respondents}

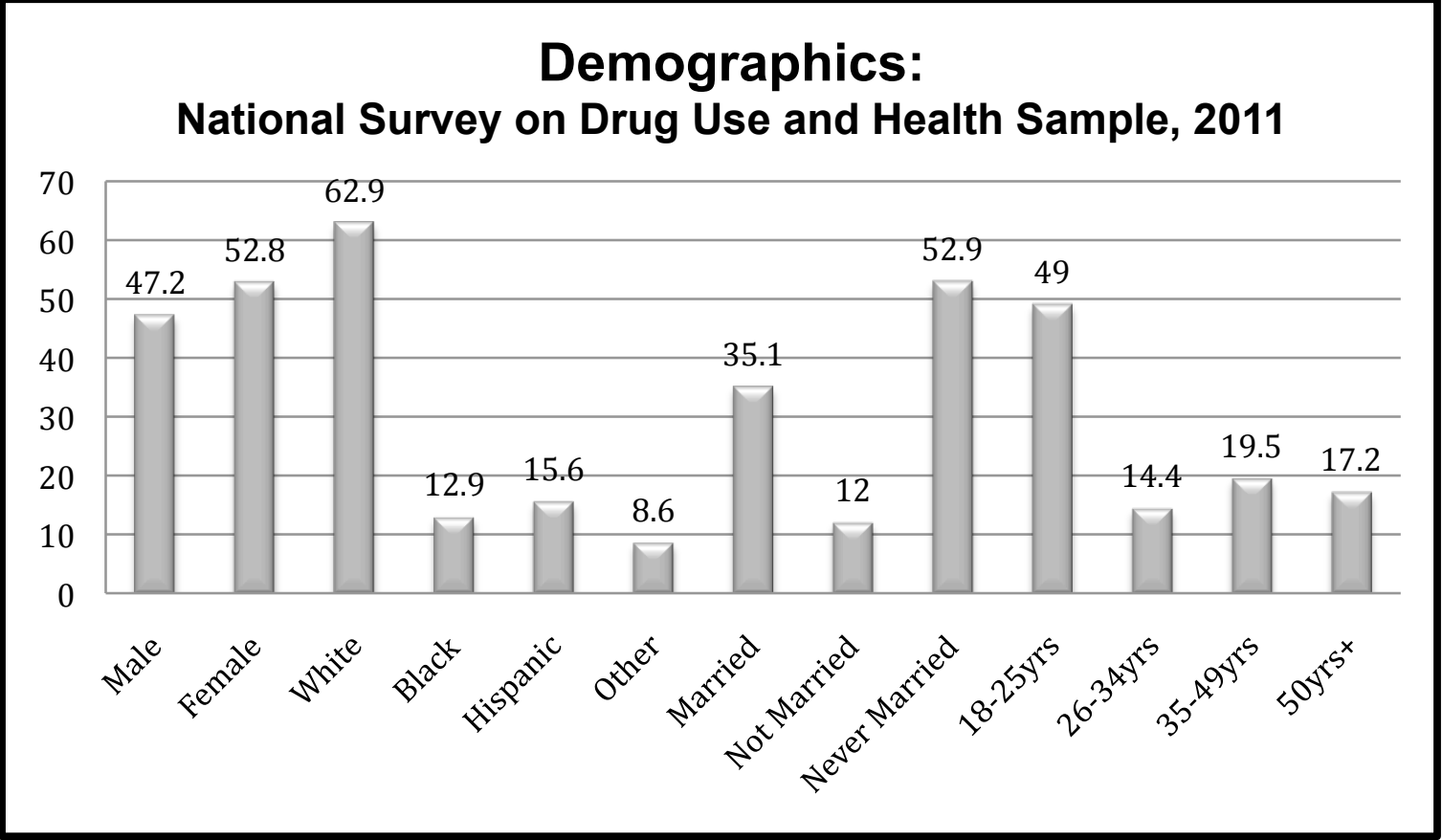

Source: National Survey on Drug Use and Health, 2011

$\mathrm{N}=39,133$ (Respondents 18yrs + ) 
(about14\%) reporting that they are between the ages of 26 and 34 years old.

A univariate analysis of the study dependent variable is displayed in Figure 2.

This analysis reveals that $18 \%$, or about 7200 , of the respondents who are 18 years and older in the 2011 NSDUH report that they have ever misused prescription painkillers.

Figure 2: Univariate Analysis by Misuse Status

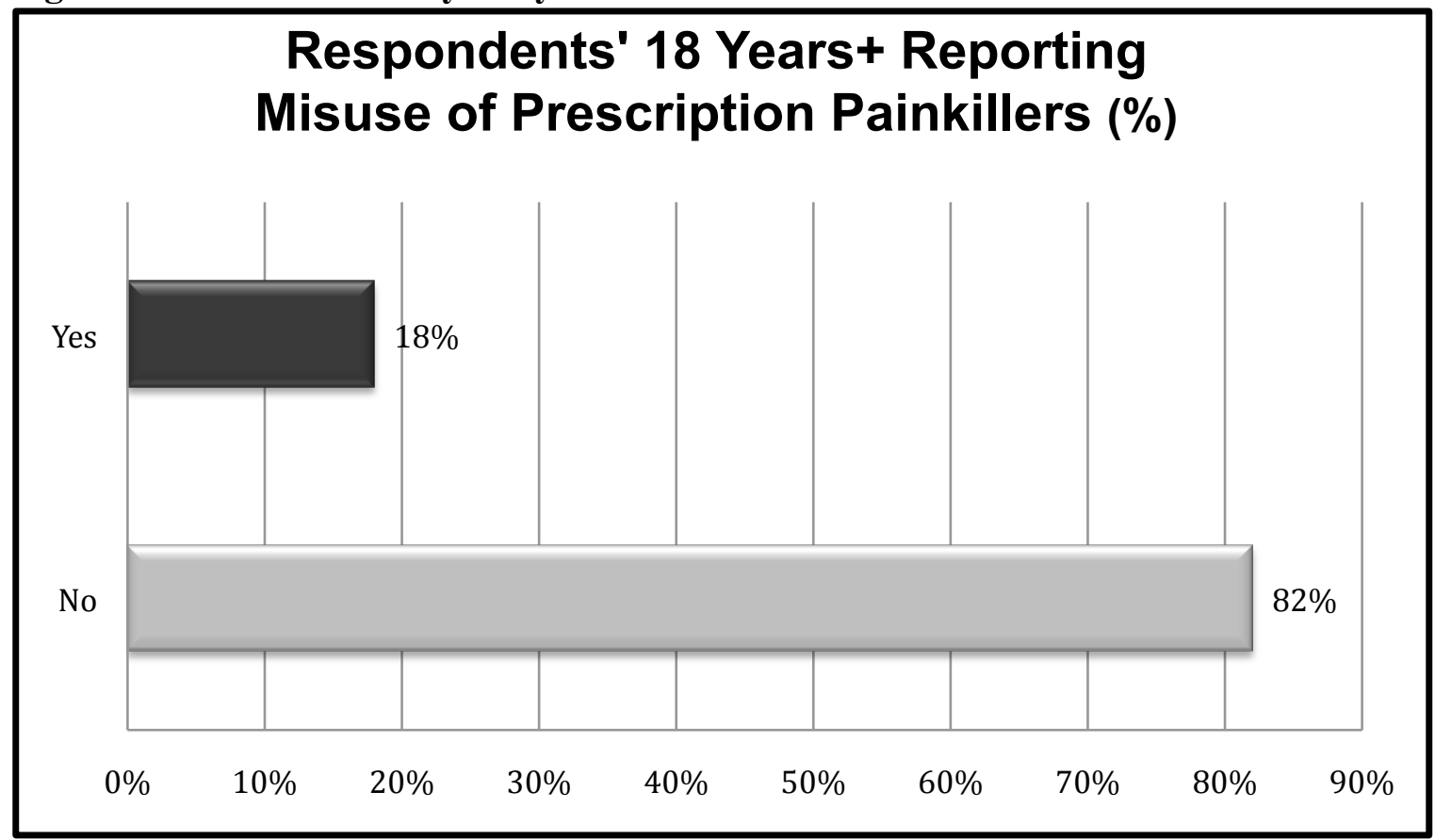

Source: National Survey on Drug Use and Health, 2011

$\mathrm{N}=39,133$

A demographic comparison of misusers to non-misusers in the population of interest is displayed in Table 1. For the study sample population, 18 years of age and older who report the misuse of prescription painkillers, nearly $55 \%$ are male, while about $45 \%$ of respondents are female. Further, $72 \%$ of misusers in the study sample are white, with about $9 \%$ being black, and $12 \%$ identifying as Hispanic. The majority of misusers 
report having never been married (65\%), while $25 \%$ are married and $10 \%$ are not married. Additionally, $60 \%$ of respondents reporting the misuse of prescription painkillers are 18-25 years old, while about $17 \%$ are between the ages of 26 and 34 years old. Another $16 \%$ of the sample population is between 35 and 49 years of age, with the fewest number of respondents (about7\%) reporting that they are 50 years of age and older.

Table 1: Sample Characteristics by Misuse Status (18+ Years)

\begin{tabular}{lrrrr}
\hline & \multicolumn{2}{c}{ Non-Misusers } & \multicolumn{2}{c}{ Misusers } \\
\cline { 2 - 5 } & \multicolumn{1}{c}{$\mathrm{N}$} & $\%$ & $\mathrm{~N}$ & $\%$ \\
\hline Sex & & & & \\
Female & 17,398 & 54.5 & 3,262 & 45.3 \\
$\quad$ Male & 14,534 & 45.5 & 3,939 & 54.7 \\
Race & & & & \\
$\quad$ White & 19,465 & 61.0 & 5,156 & 71.6 \\
Black & 4,366 & 13.7 & 656 & 9.1 \\
Hispanic & 5,244 & 16.4 & 864 & 12.0 \\
Other & 2,857 & 8.9 & 525 & 7.3 \\
Age & & & & \\
18-25 Years Old & 14,846 & 46.5 & 4,337 & 60.2 \\
26-34 Years Old & 4,397 & 13.8 & 1,229 & 17.1 \\
35-49 Years Old & 6,491 & 20.3 & 1,128 & 15.7 \\
50-64 Years Old & 3,772 & 11.8 & 447 & 6.2 \\
65+ Years Old & 2,426 & 7.6 & 60 & .8 \\
Marital Status & & & & \\
Married & 11,961 & 37.5 & 5,411 & 24.9 \\
Not Married & 3,922 & 12.3 & 741 & 10.3 \\
Never Married & 16,049 & 50.2 & 4,670 & 64.8 \\
\hline Sounyyyy
\end{tabular}

Source: National Survey on Drug Use and Health, 2011

$\mathrm{N}=39,133$

In comparison, for the study sample population 18 years of age and older who do not misuse prescription painkillers, nearly $46 \%$ are male, while about $54 \%$ of respondents are female. Further, $61 \%$ of non-misusers in the study sample are white, with nearly $14 \%$ 
being black, and about $16 \%$ identifying as Hispanic. The majority of non-misusers report having never been married (50\%), while $38 \%$ are married and $12 \%$ are not married. Additionally, $47 \%$ of non-misusers of prescription painkillers are 18-25 years old, while about $20 \%$ are between the ages of 35 and 49 years old. Another $19 \%$ of non-misusers is 50 years of age or older, with the fewest number of respondents (about14\%) reporting that they are between the ages of 26 and 34 years old. Each of these differences noted received significant $\mathrm{T}$-test results at $\mathrm{p}<.001$ level.

\section{Bivariate Analyses}

A bivariate analysis was run between the study dependent variable and gender using crosstabs. Figure 3 shows that more men than women report the misuse of prescription painkillers. Within the entire sample population for the 2011 NSDUH, 18 years and older, nearly $55 \%$ of the respondents reporting no prescription painkiller misuse are female and about $45 \%$ are male. However, the reverse is true of those respondents who say that they misuse prescription painkillers, with about 55\% being male, while $45 \%$ are female. This finding supports Hypothesis 1, which suggests women are less likely to misuse prescription painkillers than are men. These data are statistically significant and we can be $99 \%$ certain that the relationship between these variables is not the result of chance.

Further bivariate analyses were run between the gender stratified dependent variable and all other independent variables in the study. Tables 2 shows the results of a crosstab analysis between the stratified study dependent variable and marital status. For both men and women, misusers and non-misusers alike, the majority report never having 
Figure 3: Prescription Painkiller Misuse by Gender

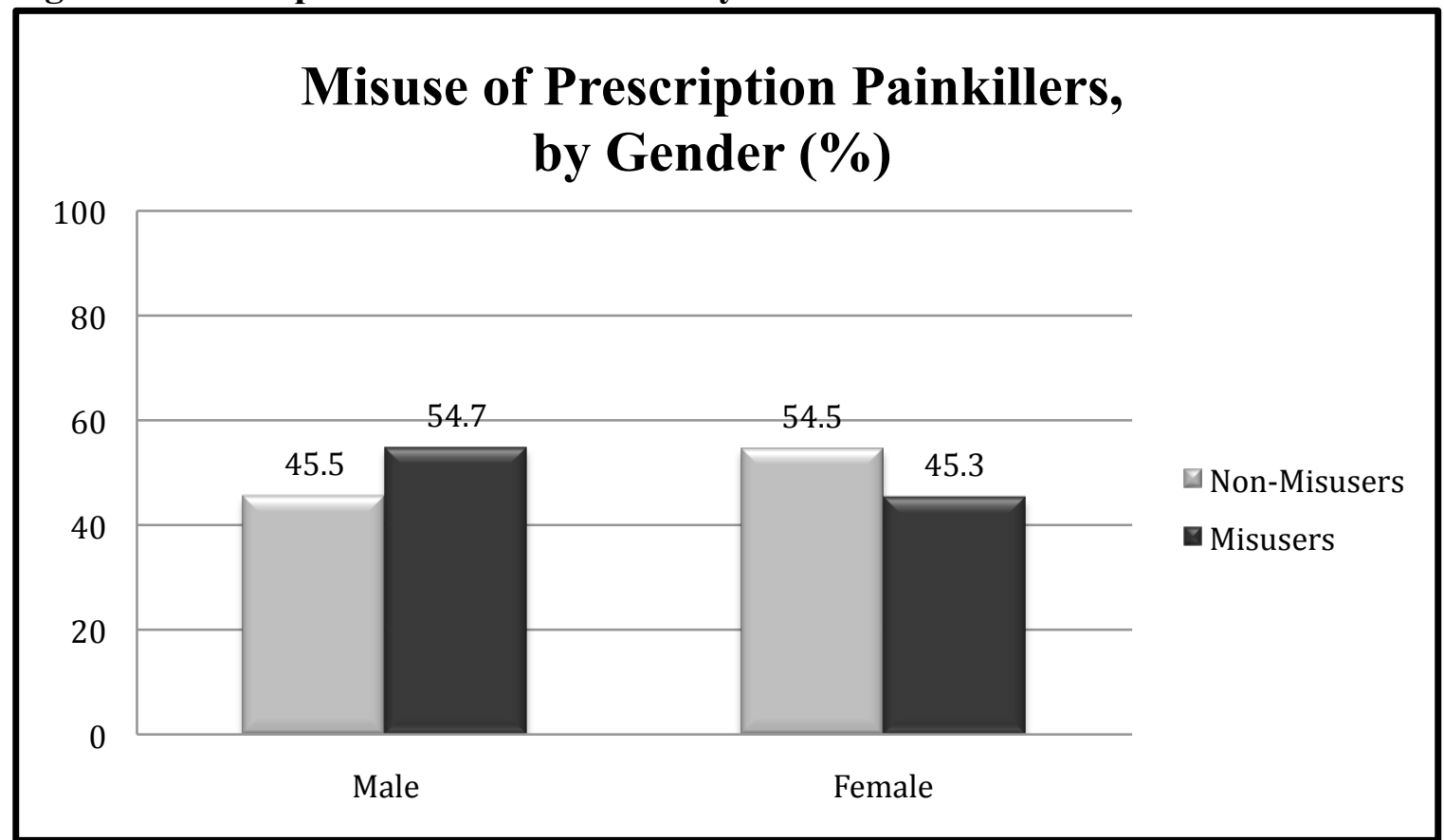

Source: National Survey on Drug Use and Health, 2011

$\mathrm{N}($ Non-Misusers $)=31,932, \mathrm{~N}($ Misusers $)=7,201$, Pearson's Chi-Square $=198.920(\mathrm{p}<.001)$

been married (men: non-misusers $=54.4 \%$, misusers $=67.6 \%$; women: non-misusers $=$ $46.8 \%$, misusers $=61.5 \%$, while the smallest percentage of respondents in the sample report that they are not currently married (see Table 2). For men, almost $37 \%$ of the non-misusers and nearly $34 \%$ of the misusers are married, while $26 \%$ of female misusers and about $38 \%$ of female non-misusers are married. This result partially supports Hypotheses 2 and 3, which state that a) married men are less likely than married women to misuse prescription painkillers and b) married women are more likely to misuse prescription painkillers than men and women who are not married. These results suggest that something is happening with gender and prescription painkiller misuse and that 
Table 2: Prescription Painkiller Misuse by Marital Status

\begin{tabular}{|c|c|c|c|c|c|c|c|c|}
\hline & \multicolumn{4}{|c|}{ Female } & \multicolumn{4}{|c|}{ Male } \\
\hline & \multicolumn{2}{|c|}{ Non-Misusers } & \multicolumn{2}{|c|}{ Misusers } & \multicolumn{2}{|c|}{ Non-Misusers } & \multicolumn{2}{|c|}{ Misusers } \\
\hline & $\mathrm{N}$ & $\%$ & $\mathrm{~N}$ & $\%$ & $\mathrm{~N}$ & $\%$ & $\mathrm{~N}$ & $\%$ \\
\hline \multicolumn{9}{|l|}{ Marital Status } \\
\hline Married & 6,649 & 38.2 & 848 & 26.0 & 5,312 & 36.5 & 942 & 33.9 \\
\hline Not Married & 2,611 & 15.0 & 407 & 12.5 & 1,311 & 9.1 & 334 & 8.9 \\
\hline Never Married & 8,138 & 46.8 & 2,007 & 61.5 & 7,911 & 54.4 & 2,663 & 67.6 \\
\hline
\end{tabular}

Source: National Survey on Drug Use and Health, 2011

Pearson's Chi-Square: F=303.266; $M=269.190(\mathrm{p}<.001)$

$\mathrm{N}=39,133$

marital status does appear to have a relationship to the misuse of these drugs. Further, these results suggest that having never been married may be important for both men and women, but perhaps more so for men. The literature suggests race and age may be less predictive of drug and alcohol misuse than are indicators of socio-economic status (Wilson 1978; Barr et al. 1993; Alarid et al. 2000). For this reason, a multivariate analysis, controlling for race and age variables will likely reveal a clearer picture of this relationship.

Table 3 displays the results of a cross tabulation between the stratified dependent variable and education. This analysis tests Hypothesis 4, which states men and women with higher levels of education are less likely to misuse prescription painkillers than are men and women with lower levels of education. For men, almost $34 \%$ of both nonmisusers and misusers are high school graduates, while about $33 \%$ of female misusers and nearly $31 \%$ of female non-misusers are high school graduates. For women, the majority of respondents reported having some college (non-misusers $=31.3 \%$, misusers $=$ $33.6 \%$ ), while fewer reported having a college degree (non-misusers $=24.1 \%$, misusers $=$ 
$18.4 \%)$. Fourteen percent of the female non-misusers and about $15 \%$ of the misusers have less than a high school degree. The results are similar for men, across misuse status, with the highest percentage of respondents having a high school diploma and the least

Table 3: Prescription Painkiller Misuse by Education

\begin{tabular}{lccrrrrrr}
\hline & \multicolumn{4}{c}{ Female } & \multicolumn{5}{c}{ Male } \\
\cline { 2 - 9 } & \multicolumn{1}{c}{ Non-Misusers } & \multicolumn{1}{c}{ Misusers } & Non-Misusers & \multicolumn{2}{c}{ Misusers } \\
\cline { 2 - 9 } & $\mathrm{N}$ & $\%$ & $\mathrm{~N}$ & $\%$ & $\mathrm{~N}$ & $\%$ & $\mathrm{~N}$ & $\%$ \\
\hline Education & & & & & & & & \\
Less Than HS & 2,443 & 14.0 & 486 & 14.9 & 2,517 & 17.3 & 753 & 19.1 \\
HS Graduate & 5,320 & 30.6 & 1,082 & 33.2 & 4,936 & 34.0 & 1,355 & 34.4 \\
Some College & 5,438 & 31.3 & 1,095 & 33.6 & 3,949 & 27.2 & 1,191 & 30.2 \\
College Grad & 4,197 & 24.1 & 599 & 18.4 & 3,132 & 21.5 & 3,772 & 20.4 \\
\hline
\end{tabular}

Source: National Survey on Drug Use and Health, 2011

Pearson's Chi-Square: $F=51.287 ; \mathrm{M}=58.964(\mathrm{p}<.001)$

$\mathrm{N}=39,133$

have less than a high school diploma. To state this another way, what this cross tabulation is telling us is that more men and women with a high school diploma are misusing prescription painkillers than are men and women with less than a high school diploma. This result does not support Hypothesis 3, which posits that as education increases, prescription painkiller misuse decreases. It is important to acknowledge the inability to conclude anything about education as it pertains to presciption painkiller misuse, while the crosstab analysis is still statistically significant. Given the large size of the project, with nearly 60,000 respondents, statistically significant results are relatively easy to achieve. However, given the suggested importance of socio-economic indicators and their relationship to drug an alcohol misuse, the education variable will be included 
in a multivariate analysis. This analysis may be bettter suited to test whether level of education is specifically associated with prescription painkiller misuse.

Figures 4 and 5 illustrate the results of a crosstab analysis between the stratified dependent variable and the variable for household income. These results indicate that

Figure 4: Prescription Painkiller Misuse by Income - Female

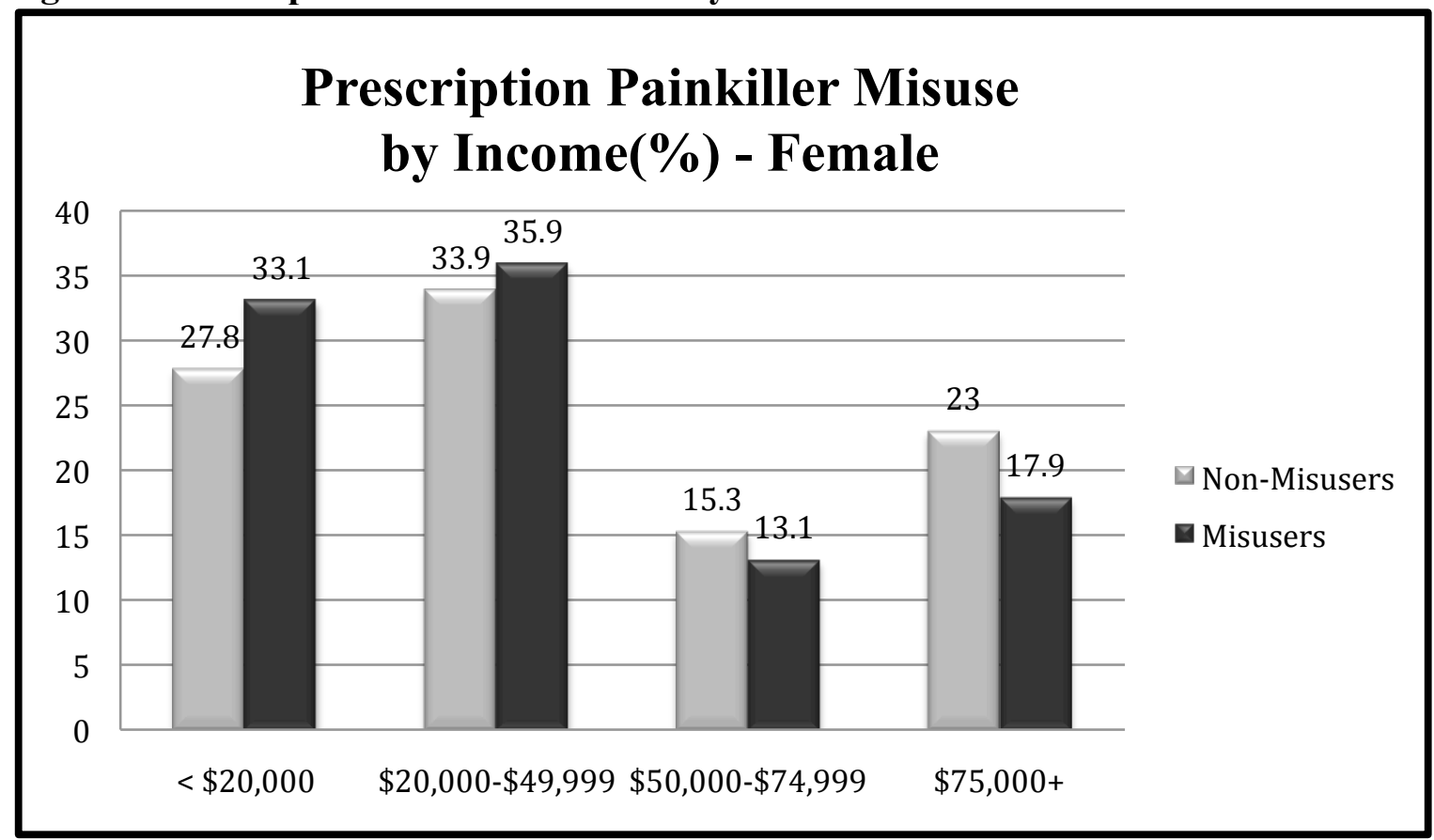

Source: National Survey on Drug Use and Health, 2011

$\mathrm{N}($ Non-Misusers $)=17,398, \mathrm{~N}($ Misusers $)=3,262$, Pearson's Chi-Square $=71.122(\mathrm{p}<.001)$

within the female population of respondents 18 years of age and older, nearly $28 \%$ of those respondents saying that they do not misuse prescription painkillers have a family income of less than $\$ 20,000$, while $23 \%$ report a family income of $\$ 75,000$ or more. Of those respondents who do misuse prescription painkillers, about 33\% report having a family income of less than $\$ 20,000$, with about $18 \%$ reporting a family income of 
$\$ 75,000$ or more. For the male respondents 18 years of age and older, nearly $24 \%$ of those respondents saying that they do not misuse prescription painkillers have a family income of less than $\$ 20,000$, about $26 \%$ report a family income of $\$ 75,000$ or more. Of those respondents who do misuse prescription painkillers, about 26\% report having a family income of less than $\$ 20,000$, with nearly $23 \%$ reporting a family income of $\$ 75,000$ or more. These results partially support Hypothesis 5 , which states men and women with higher income are less likely to misuse prescription painkillers than are men and women with lower income because for both men and women. Though the highest misuse is reported for the lowest income category, more respondents with the highest household income $(\$ 75 \mathrm{k}+)$ report the misuse of prescription painkillers than do those

Figure 5: Prescription Painkiller Misuse by Income - Male

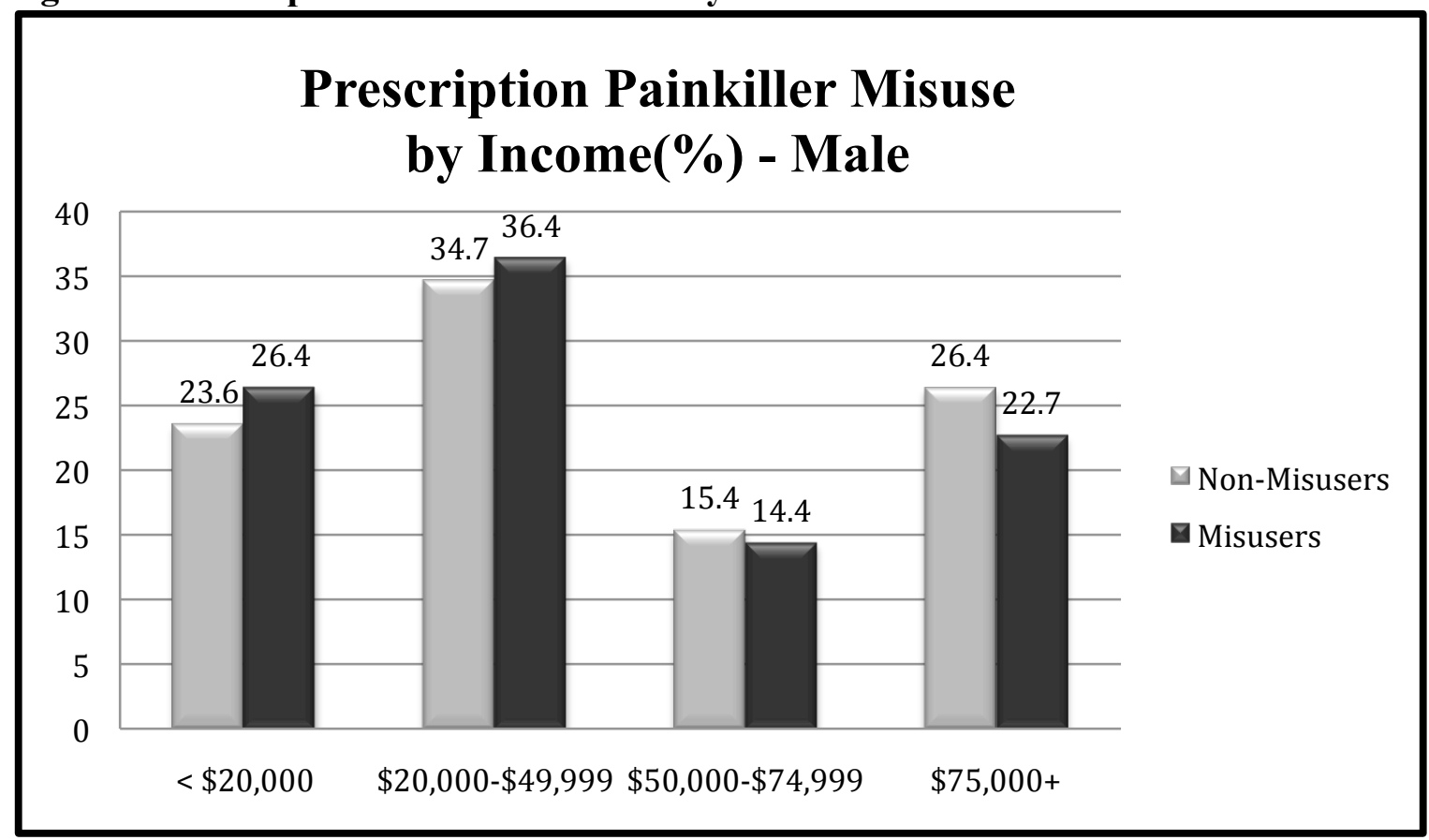

Source: National Survey on Drug Use and Health, 2011

$\mathrm{N}($ Non-Misusers $)=14,534, \mathrm{~N}$ (Misusers) $=3,939$, Pearson's Chi-Square $=30.630(\mathrm{p}<.001)$ 
with the next highest household income $(\$ 50,000-\$ 74,999)$. These data are statistically significant and, again, we can be $99 \%$ certain that the relationship between these variables is not the result of chance.

Table 4 shows a cross tabulation between the stratified dependent variable and work status. For women, nearly $62 \%$ of non-misusers and about $64 \%$ of misusers report that they are working, while about $38 \%$ of non-misusers and $36 \%$ of misuers report they are not working. For men, almost $70 \%$ of non-misusers and close to $71 \%$ of misusers say they have a job, while about $30 \%$ of non-misusers and almost $29 \%$ of misusers say that they are not currently working. This result does not support Hypothesis 6, which states men and women who are working are less likely to misuse prescription painkillers than are men and women who are not working. Further, the result for men is not significant, while the result for women is significant at the $\mathrm{p}<.05$ level. The work variable will be included in a multivariate analysis, which may be better suited to test whether employment status is specifically associated with prescription painkiller misuse.

\section{Table 4: Prescription Painkiller Misuse by Work Status}

\begin{tabular}{lcccccccc}
\hline & \multicolumn{4}{c}{ Female } & \multicolumn{5}{c}{ Male } \\
\cline { 2 - 10 } & \multicolumn{2}{c}{ Non-Misusers } & \multicolumn{2}{c}{ Misusers } & Non-Misusers & \multicolumn{2}{c}{ Misusers } \\
\cline { 2 - 9 } & $\mathrm{N}$ & $\%$ & $\mathrm{~N}$ & $\%$ & $\mathrm{~N}$ & $\%$ & $\mathrm{~N}$ & $\%$ \\
\hline Work Status & & & & & & & & \\
$\quad$ Working & 10,731 & 61.7 & 2,082 & 63.8 & 10,130 & 69.7 & 2,804 & 71.2 \\
$\quad$ Not Working & 6,667 & 38.3 & 1,180 & 36.2 & 4,404 & 30.3 & 1,135 & 28.8 \\
\hline
\end{tabular}

Source: National Survey on Drug Use and Health, 2011

Pearson's Chi-Square: $\mathrm{F}=5.372$ ( $\mathrm{p}<.05) ; \mathrm{M}=3.264$ (not sig.)

$\mathrm{N}=39,133$ 
Figures 6 and 7 show the results of crosstab analyses between the stratified dependent variable and an index created to measure the importance of the respondents'

Figure 6: Index of Importance of Religious Beliefs - Male

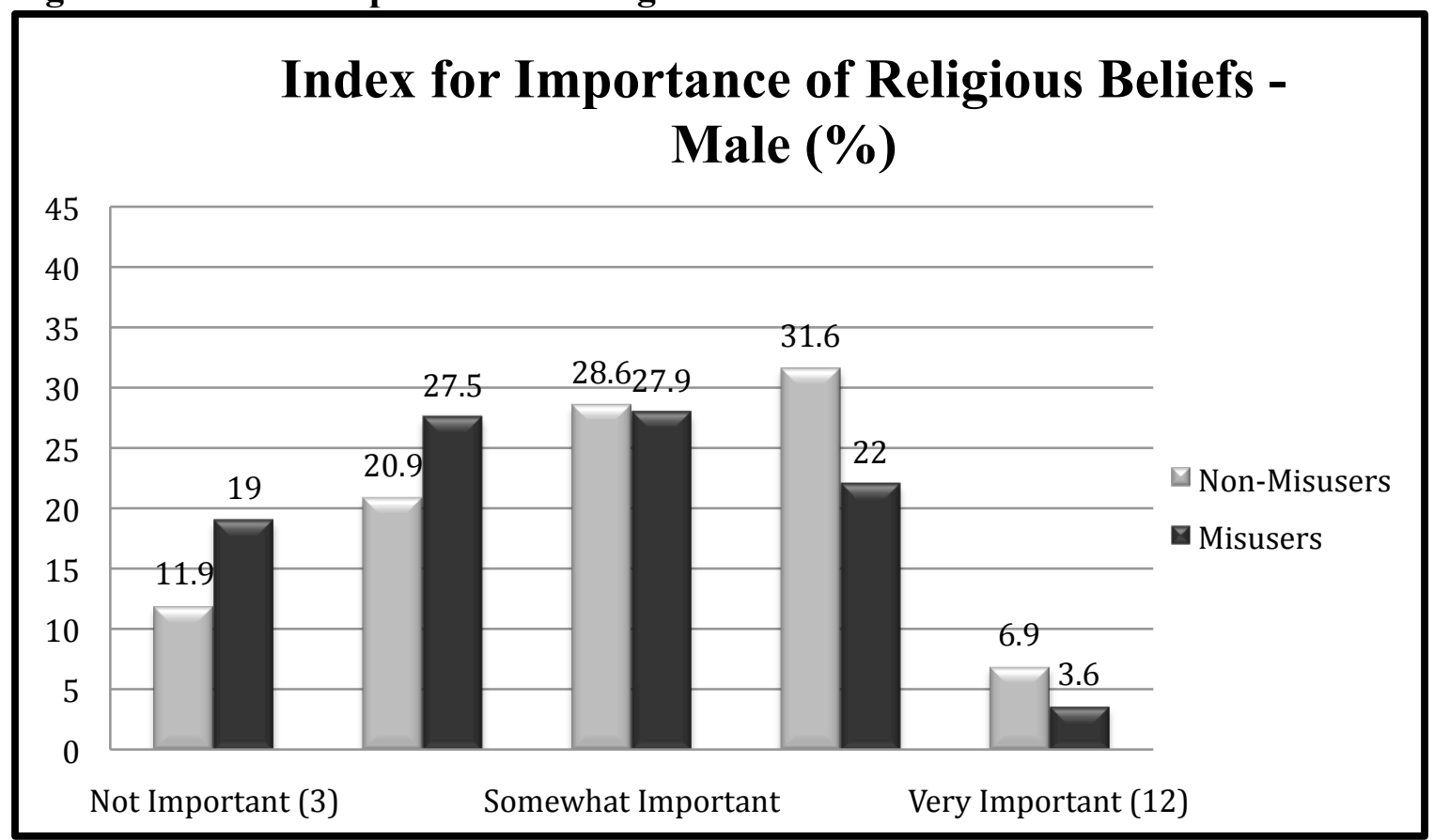

Source: National Survey on Drug Use and Health, 2011

$\mathrm{N}($ Non-Misusers $)=14,218, \mathrm{~N}$ (Misusers) $=3,872$, Pearson's Chi-Square $=380.677(\mathrm{p}<.001)$

spiritual beliefs. These analyses test Hypotheses 7, which states men and women with higher levels of religiosity are less likely to misuse prescription painkillers than are men and women with lower levels of religiosity. These data show that, for misusers, about $46 \%$ of men and about $41 \%$ of women say that religious beliefs are minimally or not important, while nearly $26 \%$ of men and $30 \%$ of women say that religious beliefs are important or very important. About $28 \%$ of male misusers and nearly $29 \%$ of female misusers say that their religious beliefs are somewhat important. For non-misusers, 
Figure 7: Index of Importance of Religious Beliefs - Female

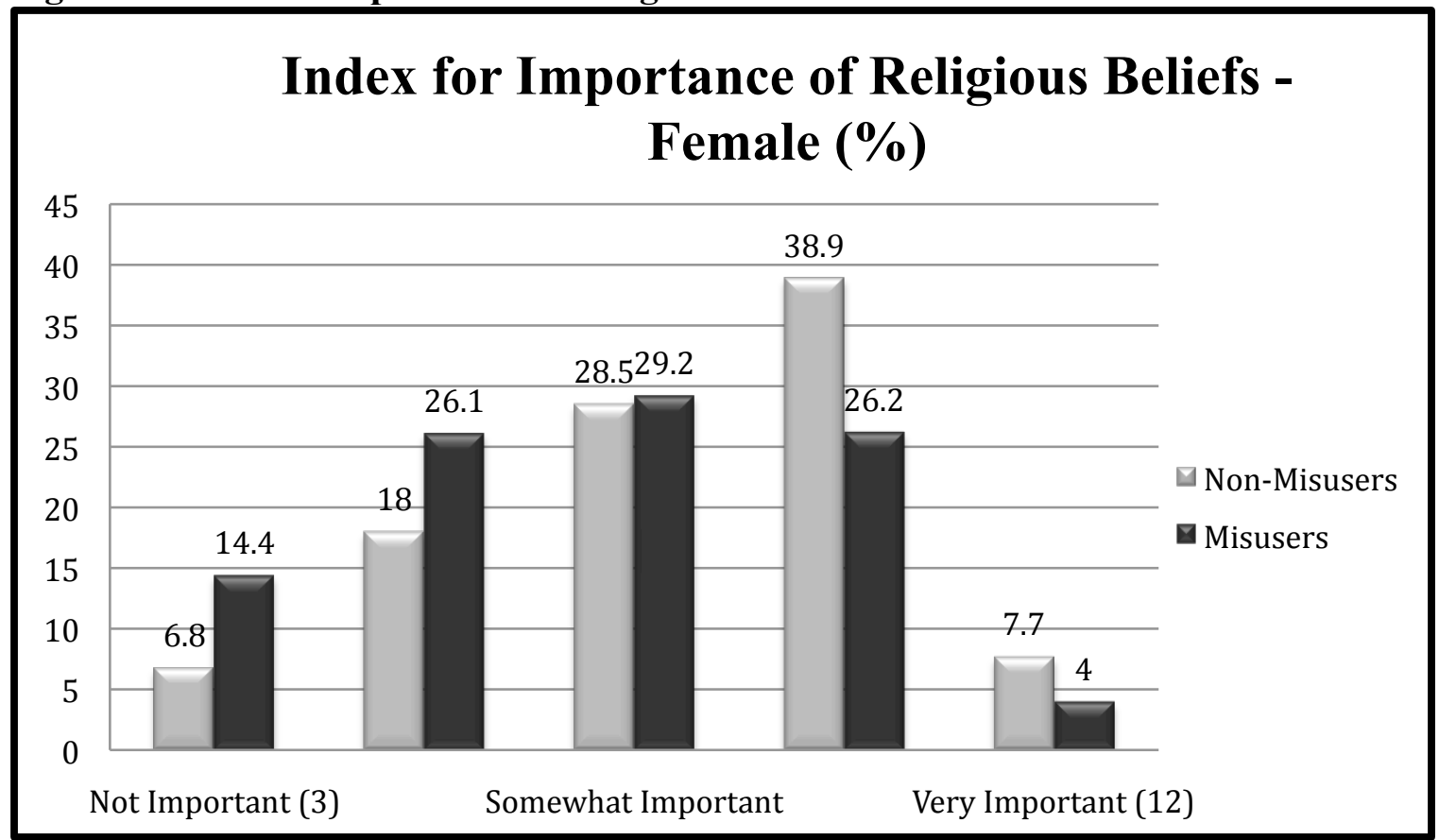

Source: National Survey on Drug Use and Health, 2011

$\mathrm{N}($ Non-Misusers $)=17,005, \mathrm{~N}$ (Misusers) $=3,215$, Pearson's Chi-Square $=499.212(\mathrm{p}<.001)$

about $32 \%$ of men and about $25 \%$ of women say that religious beliefs are minimally or not important, while almost $40 \%$ of men and about $47 \%$ of women say that religious beliefs are important or very important. About $28 \%$ of male and female misusers say that their religious beliefs are somewhat important. In other words, respondents who say that their religious beliefs are very important report less misuse of prescription painkillers than do respondents who say they their beliefs are not important.

Table 5 shows a cross tabulation between the stratified dependent variable and frequency of church attendance. This further tests Hypotheses 7. Results show, for nonmisusers, about $15 \%$ of females and $11 \%$ of males attend church frequently $(52+$ times per year) and $29 \%$ of females and $25 \%$ of males attend often (less than 52 , but more than 
25 times per year), while about $56 \%$ of females and $64 \%$ of males rarely, or never attend.

For misusers, about $7 \%$ of females and $6 \%$ of males attend church frequently and about $22 \%$ of females and nearly $19 \%$ of males attend often, while about $71 \%$ of females and nearly $68 \%$ of males rarely, or never attend. In other words, both male and female respondents who rarely or never attend church are more likely to misuse prescription painkillers, while those who attend often or frequently are less likely to

Table 5: Prescription Painkiller Misuse by Church Attendance

\begin{tabular}{lcrrrrrrr}
\hline & \multicolumn{4}{c}{ Female } & \multicolumn{5}{c}{ Male } \\
\cline { 2 - 9 } & \multicolumn{1}{c}{ Non-Misusers } & \multicolumn{1}{c}{ Misusers } & Non-Misusers & \multicolumn{2}{c}{ Misusers } \\
\cline { 2 - 9 } & $\mathrm{N}$ & $\%$ & $\mathrm{~N}$ & $\%$ & $\mathrm{~N}$ & $\%$ & $\mathrm{~N}$ & $\%$ \\
\hline Attend Church & & & & & & & & \\
$\quad$ Never & 5,908 & 34.2 & 1,503 & 46.3 & 6.241 & 43.2 & 2,309 & 45.1 \\
Rarely & 3,724 & 21.5 & 807 & 24.8 & 3,025 & 20.9 & 923 & 23.6 \\
Often & 5,022 & 29.1 & 709 & 21.8 & 3,596 & 24.9 & 738 & 18.8 \\
Frequently & 2,631 & 15.2 & 230 & 7.1 & 1,578 & 10.9 & 219 & 5.6 \\
\hline
\end{tabular}

Source: National Survey on Drug Use and Health, 2011

Pearson's Chi-Square: F=305.418; $\mathrm{M}=200.672(\mathrm{p}<.001)$

$\mathrm{N}=38,893$

misuse these drugs. Further, more female non-misusers than male non-misusers attend church frequently or often. These findings support Hypotheses 7, however, a multivariate analysis is needed to determine whether religiosity and church attendance remain significant when other variables are controlled for.

\section{Regression Analyses}

Variables associated with prescription painkiller misuse among men and women were examined in the full sample (not including individuals between the ages of 12 and 
17 years old) and the results, with adjusted odds ratios, are displayed in Table 6. First, it is important to note that a significant odds ratio with a value below 1 indicates that the independent variable reduces the odds of the dependent variable having a value of 1 (misuse of prescription painkillers), and an odds ratio greater than 1 indicates an increase in these odds. Subtracting 1 from the ratio and multiplying by 100 gives the percent change in the odds of the dependent variable having a value of 1 . Thus, the adjusted odds ratios displayed in Table 6 indicate that the following variables are significant predictors of increased prescription painkiller misuse: not married [AOR 1.19, $\mathrm{p}<.05$ ], never being married [AOR 1.49, $\mathrm{p}<.001$ ], education [less than high school vs. high school graduate AOR 1.10, $<<.05]$, and currently working [AOR 1.17, $\mathrm{p}<.001]$. Variables associated with a statistically significant decrease in the odds of misusing prescription painkillers are female gender [adjusted odds ratio (AOR) .77, $\mathrm{p}<.001$ ], race [compared to White: being Black AOR .56, $\mathrm{p}<.001$, being Hispanic AOR .56, $\mathrm{p}<.001$, being Other Race AOR .66, $\mathrm{p}<.001$ ], age [AOR .97, $\mathrm{p}<.001$ ], education [college graduate vs. high school graduate AOR $0.80, \mathrm{p}<.001$ ], placing importance on religious/spiritual beliefs [AOR .91, $<<.001$ ], and frequency of church attendance [compared to never attending: attending often AOR $.81, \mathrm{p}<.001$, attending frequently AOR $.60, \mathrm{p}<.001]$.

Next, in order to explore what independent variables may be predictive of prescription painkiller misuse within each gender subgroup, the same variables of interest 


\section{Table 6: Logistic Regression of Prescription Painkiller Misuse}

Variable

Demographic Indicators

Female

Black

Hispanic

Other Race

White

Age

Social Bond Variables

Not Married

Never Married

Married

Educ-LTHS

Educ-SC

Educ-CG

Educ-HS

Household Income

Working

Religiosity

Attend Church-Rarely

Attend Church-Often

Attend Church-Frequently

Attend Church-Never

-2 Log likelihood

Number of Cases

\section{AOR}

$.77 * *$

$.56 * *$

$.57 * *$

$.66^{* *}$

Ref

$.97 * *$

$1.19 *$

$1.49 * *$

Ref

$1.10 *$

1.04

$.80 * *$

Ref

$.92 * *$

$1.17 * *$

$.91 * *$

1.03

$.81^{* *}$

$.60 * *$

Ref

Note: Only odds ratios are presented.

$* * \mathrm{p}<.001 ; * \mathrm{p}<.05$

were examined in separate multivariate regression models with the inclusion of interaction terms. Regression models 1 through 11, in tables 7 and 8, include interactions of gender (female) and all of the various independent variables in order to test the 
hypothesized gender differences in this study. Social bond variables include 'not married' and 'never married,' with 'married' as the reference category, 'less than high school,' 'some college,' and 'college graduate,' compared to 'high school graduate,' 'household income,' 'working,' compared to 'not working,' 'religiosity,' and 'rarely attend church,' 'often attend church,' and 'frequently attend church,' with 'never attend church' as the reference category. Control variables for race and age are included in each model.

The first two models in Table 7 include interactions between gender (female) and variables pertaining to marital status. In model 1, the Female $\mathrm{x}$ Not Married interaction is not statistically significant, which indicates not being married has little impact on prescription painkiller misuse for women. Because this model controls for women who are not married, we can interpret the significant positive odds ratio $(\mathrm{AOR}=1.52 ; \mathrm{p}<.001)$ for the main effect in model 1 as indicating that, compared to men and women who are married, men who are not married are 52\% more likely to misuse prescription painkillers.

Model 2 shows the interaction for Female x Never Married. Similar to the interaction in model 1, the Female x Never Married interaction is not statistically significant, suggesting that never having been married has little effect on the misuse of prescription painkillers for women. This model controls for women who have never been married. As such, the significant positive odds ratio for the main effect (AOR $=1.69$; $\mathrm{p}<.001$ ) suggests that never having been married corresponds to a $69 \%$ increase in the 
Table 7:

Logistic Regression of Prescription Painkiller Misuse with Interaction Terms

\begin{tabular}{|c|c|c|c|c|c|c|}
\hline Variable & Model 1 & Model 2 & Model 3 & Model 4 & Model 5 & Model 6 \\
\hline \multicolumn{7}{|l|}{$\underline{\text { Demographics }}$} \\
\hline Female & $.73 * *$ & $.68^{* *}$ & $.71 * *$ & $.72 * *$ & $.71 * *$ & $.80 * *$ \\
\hline Black $^{\mathrm{a}}$ & $.50 * *$ & $.50 * *$ & $.53^{* *}$ & $.52 * *$ & $.53 * *$ & $.51 * *$ \\
\hline Hispanic $^{a}$ & $.58 * *$ & $.58^{* *}$ & $.56^{* *}$ & $.56 * *$ & $.56^{* *}$ & $.55^{* *}$ \\
\hline Other Race $^{a}$ & $.64 * *$ & $.64 * *$ & $.66^{* *}$ & $.66^{* *}$ & $.66^{* *}$ & $.64 * *$ \\
\hline $\mathrm{Age}^{\mathrm{b}}$ & $.96^{* *}$ & $.96^{* *}$ & $.92 * *$ & $.92 * *$ & $.92 * *$ & $.92 * *$ \\
\hline \multicolumn{7}{|l|}{ Social Bonds } \\
\hline Never Married & $1.77 * *$ & & & & & \\
\hline Not Married & & $1.40 * *$ & & & & \\
\hline Some College & & & 1.03 & & 1.03 & \\
\hline College Grad & & & $.77 * *$ & $.77 * *$ & & \\
\hline Less Than HS & & & & $1.09 *$ & $1.09 *$ & \\
\hline \multicolumn{7}{|l|}{ Interaction Terms } \\
\hline Not Married $^{\mathrm{c}}$ & $1.52 * *$ & & & & & \\
\hline FemaleXNot Marr & .85 & & & & & \\
\hline Never Married $^{\mathrm{c}}$ & & $1.69 * *$ & & & & \\
\hline FemaleXNever Marr & & 1.10 & & & & \\
\hline Educ-LTHS ${ }^{\mathrm{d}}$ & & & 1.10 & & & \\
\hline FemaleXLTHS & & & .98 & & & \\
\hline Educ-SC ${ }^{\mathrm{d}}$ & & & & 1.06 & & \\
\hline FemaleXSC & & & & .94 & & \\
\hline Educ-CG ${ }^{\mathrm{d}}$ & & & & & $.78 * *$ & \\
\hline FemaleXCG & & & & & .98 & \\
\hline Income $^{e}$ & & & & & & $.91 * *$ \\
\hline FemaleXIncome & & & & & & $.94 *$ \\
\hline-2 Log likelihood & 36201.945 & 36202.467 & 36360.281 & 36359.172 & 36360.321 & 36321.841 \\
\hline Number of Cases & 39,133 & 39,133 & 39,133 & 39,133 & 39,133 & 39,133 \\
\hline
\end{tabular}


odds of prescription painkiller misuse for men, when compared to men and women who are married.

Models 3 through 5 in Table 7 include interactions between gender (female) and variables pertaining to educational attainment. In all three models, Female x EducLTHS, Female $\mathrm{x}$ Educ-SC, Female $\mathrm{x}$ Educ-CG, the interaction is not statistically significant, which indicates having less than a high school diploma, having some college, and being a college graduate all have little impact on prescription painkiller misuse for women. However, because these models control for women who have less than a high school diploma, some college, or a college degree, respectively, the significant odds ratio for the main effect in Model $5(\mathrm{AOR}=.78 ; \mathrm{p}<.001)$ suggests that, compared to men and women with a high school diploma, men who are college graduates are $22 \%$ less likely to misuse prescription painkillers.

The interaction Female x Income in Model 6 (see Table 7) measures the effect of income on prescription painkiller misuse by gender. Because this interaction effect is significant, this indicates that there is variation between men and women in the effects of income on the misuse of prescription painkillers. More specifically, the effect of income shows additional decreasing odds of prescription painkiller misuse for women, compared to men (a reduction of $6 \%$ for each step up in income). Another way to look at this interaction effect would be to calculate the predicted probability of misusing prescription painkillers for men and women. The mean score for income in this study is 2.46 . As previously stated, the income ranges are: $1=$ Less than $\$ 20,000,2=\$ 20,000-\$ 49,999,3$ $=\$ 50,000-\$ 74,999$, and $4=\$ 75,000$ or more 
Table 8:

Logistic Regression of Prescription Painkiller Misuse with Interaction Terms

\begin{tabular}{|c|c|c|c|c|c|}
\hline Variable & Model 7 & Model 8 & Model 9 & Model 10 & Model 11 \\
\hline Demographics & . & & & & \\
\hline Female & $.74 * *$ & $.75^{* *}$ & $.75^{* *}$ & $.74 * *$ & .95 \\
\hline Black $^{\mathrm{a}}$ & $.55^{* *}$ & $.57^{* *}$ & $.58^{* *}$ & $.58 * *$ & $.63^{* *}$ \\
\hline Hispanic $^{a}$ & $.58^{* *}$ & $.58^{* *}$ & $.58^{* *}$ & $.58^{* *}$ & $.62^{* *}$ \\
\hline Other Race ${ }^{a}$ & $.66^{* *}$ & $.65^{* *}$ & $.65^{* *}$ & $.64 * *$ & $.69^{* *}$ \\
\hline $\mathrm{Age}^{\mathrm{b}}$ & $.91^{* *}$ & $.91^{* *}$ & $.91 *$ & $.91^{* *}$ & $.92 * *$ \\
\hline Social Bonds & & & & & \\
\hline Church-Rarely & & & $.91^{*}$ & $.91^{*}$ & \\
\hline Church-Often & & $.61^{* *}$ & & $.61^{* *}$ & \\
\hline Church-Frequently & & $.40^{* *}$ & $.40^{* *}$ & & \\
\hline Interaction Terms & & & & & \\
\hline Working $^{\mathrm{c}}$ & $1.11^{*}$ & & & & \\
\hline FemaleXWorking & .95 & & & & \\
\hline Church-Rarely $^{\mathrm{d}}$ & & .93 & & & \\
\hline FemaleXCHRarely & & .95 & & & \\
\hline Church-Often ${ }^{\mathrm{d}}$ & & & $.62 * *$ & & \\
\hline FemaleXCHOften & & & .96 & & \\
\hline Church-Freq ${ }^{\mathrm{d}}$ & & & & $.42 * *$ & \\
\hline FemaleXCHFreq & & & & .89 & \\
\hline Religiosity & & & & & $.90^{* *}$ \\
\hline FemaleXReligiosity & & & & & $.97 *$ \\
\hline $\begin{array}{l}-2 \text { Log likelihood } \\
\text { Number of Cases }\end{array}$ & $\begin{array}{l}36420.470 \\
39,133\end{array}$ & $\begin{array}{l}35766.687 \\
38,893\end{array}$ & $\begin{array}{l}35767.015 \\
38.893\end{array}$ & $\begin{array}{l}35766.257 \\
38.893\end{array}$ & $\begin{array}{l}35228.775 \\
38,310\end{array}$ \\
\hline
\end{tabular}

${ }^{a}$ Reference is 'White'; 'Age: '12-17 yrs. old' excluded; 'Reference is 'not working'; ' $R$ eference is 'Never Attend'

Using these categories, a mean income is about $\$ 35,000$. The log-odds for females with mean income is $-.445[0.165+(-0.095 * 2.46)+(-0.224 * 1)+(-0.062 * 2.46 * 1)]$, for males with mean income the log-odds is $-.069[0.165+(-0.095 * 2.46)+(-0.224 * 0)+(-0.062 * 2.46 * 0)]]$. 
The equation for calculating the probability of misuse for females is $\operatorname{EXP}(-$ $.445) /(1+(\operatorname{EXP}(-.445)))=.390$; for males, the equation for calculating the probability of misuse is $\operatorname{EXP}(-.069) /(1+(\operatorname{EXP}(-.069)))=.483$. In other words, females with mean income of $2.46(\sim 35,000)$ have a $39.0 \%$ chance of misusing prescription painkillers, while males with the same income have a $48.3 \%$ chance of prescription painkiller misuse. In order to examine how different levels of income affect the probability of misusing prescription painkillers for females and males, using these same equations, calculations were made for females and males with an income of less than $\$ 20,000, \$ 50-\$ 74,999$, and

Figure 8: Predicted Probability of Misuse - Gender x Income

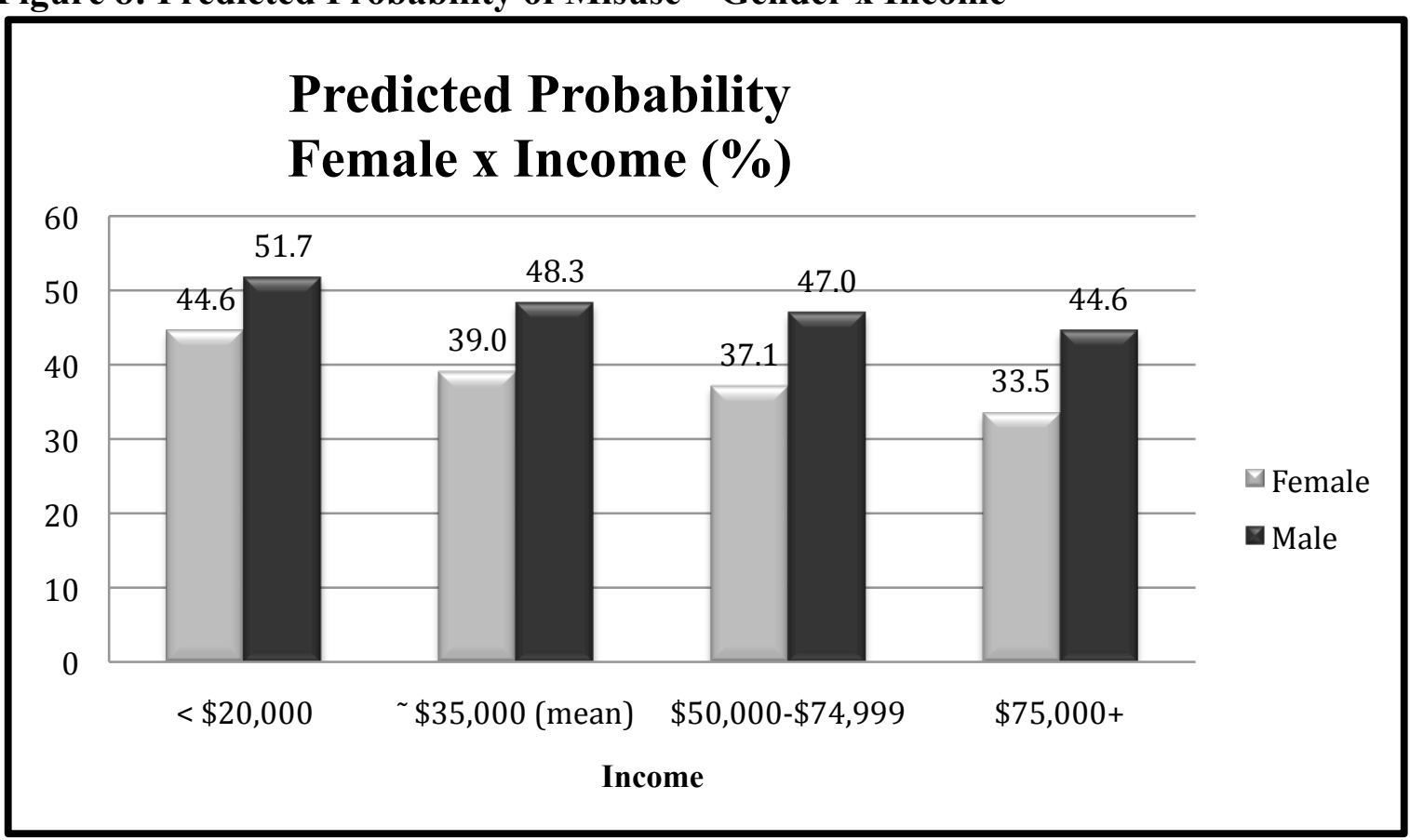

Source: National Survey on Drug Use and Health, 2011

$\$ 75,000$ or more. The results of these calculations are shown in Figure 8. Though increased income decreases the predicted probability of prescription painkiller misuse for 
both men and women, these data show a stronger effect for women than for men. For example, the decrease in the predicted probability for prescription painkiller misuse between women who have income of less than $\$ 20,000$ and women earning $\$ 75,000+$ is $25 \%$, while for men the decrease is $14 \%$. As previously stated, this difference between men and women is statistically significant.

In model 7 (Table 8), the Female $\mathrm{x}$ Working interaction is not statistically significant, which indicates being employed has little impact on prescription painkiller misuse for women. Because this model controls for women who are working, we can interpret the significant positive odds ratio $(\mathrm{AOR}=1.11 ; \mathrm{p}<.05)$ for the main effect in model 7 as indicating that for men, compared to men and women who are not working, having a job is significantly associated with an $11 \%$ increase in the odds of misusing prescription painkillers.

Models 8 through 10 in Table 8 include interactions between gender (female) and variables pertaining to church service attendance. In all three models, Female x CHRarely, Female $\mathrm{x}$ CHOften, and Female $\mathrm{x}$ CHFreq, the interaction is not statistically significant, which indicates attending church rarely, often, or frequently has little impact on prescription painkiller misuse for women. Additionally, the main effect for Model 8 is not significant. However, because Models 9 and 10 control for women who attend church often or frequently, we can interpret the significant odds ratios for the main effect in each model as follows: 
Model $9(\mathrm{AOR}=.62 ; \mathrm{p}<.001)$ : suggests that, compared to men and women who never attend church, attending church often decreases the likelihood of misusing prescription painkillers by $30 \%$ for men.

Model $10(\mathrm{AOR}=.42 ; \mathrm{p}<.001)$ : suggests that, compared to men and women who never attend church, attending church frequently decreases the likelihood of misusing prescription painkillers by $52 \%$ for men.

These results indicate that, for men but not women, attending church often and attending church frequently are both significantly associated with a decrease in the likelihood of misuse of prescription painkillers, partially support hypothesis 7 .

The interaction Female x Religiosity in Model 11 (see Table 8) measures the effect of increasing levels of religiosity on prescription painkiller misuse by gender. Because the interaction effect is significant, similar to the interaction for Female $\mathrm{x}$ Income, we can assume that there is variation between men and women in the effects of religiosity on the misuse of prescription painkillers. More specifically, the effect on prescription painkiller misuse decreases more significantly for women with higher levels of religiosity (a reduction of 3\% for each step up in importance of beliefs). The mean for the religiosity index in the study is 8 . The log-odds for females with mean religiosity is $.592[0.579+(-0.107 * 8)+(-0.051 * 1)+(-0.033 * 8 * 1]$, for males with mean religiosity the log-odds is $-.277[0.579+(-0.107 * 8)+(-0.051 * 0)+(-0.033 * 8 * 0]$. The equation for calculating the probability of misuse for females is $\operatorname{EXP}(-.592) /(1+(\operatorname{EXP}(-.592)))=.356$; for males, the equation for calculating the probability of misuse is $\operatorname{EXP}(-.277) /(1+(\operatorname{EXP}(-$ $.277)))=.431$. In other words, a female with mean religiosity of 8 has a $35.6 \%$ chance of misusing prescription painkillers, while a male with a mean religiosity of 8 has a $43.1 \%$ 
chance of prescription painkiller misuse. In order to examine how different levels of religiosity affect the probability of misusing prescription painkillers for females and males, using these same equations, calculations are made for females and males with religiosity index scores of 3 and 12. The results of these calculations are shown in Figure 9.

For females with a religiosity index score of 3 , the probability of misusing prescription painkillers is about $53 \%$ (see Figure 9). As was previously stated, females with a religiosity index score of 8 have a $35.6 \%$ chance of prescription painkiller misuse and in the last calculation, for a religiosity index score of 12 , females have a $24 \%$ probability of misusing these drugs. For males with a religiosity index score of 3 , there is about a $56 \%$ chance of prescription painkiller misuse; for a score of 8 , a $43.1 \%$ chance; and a 33\% chance of the misuse of prescription painkillers for males with a religiosity index score of 12. These data show that for both females and males, as the level of importance of religious/spiritual beliefs increases, there is a decrease in the likelihood that they will misuse prescription painkillers. However, females with higher religiosity index scores are especially unlikely, relative to males with similar religiosity scores, to participate in prescription painkiller misuse. For example, the decrease in the predicted probability for prescription painkiller misuse between women who have religiosity index score of 3 and women with a mean religiosity index score (8) is $31 \%$, while for men the decrease is $23 \%$. As previously stated, this difference between men and women is statistically significant. Hypotheses 6 and 7 are supported by these results. 
Although the interaction effects themselves aren't all statistically significant, the fact that the main effects are significant is important to note. For example, although the

Figure 9: Predicted Probability of Misuse - Gender x Religiosity

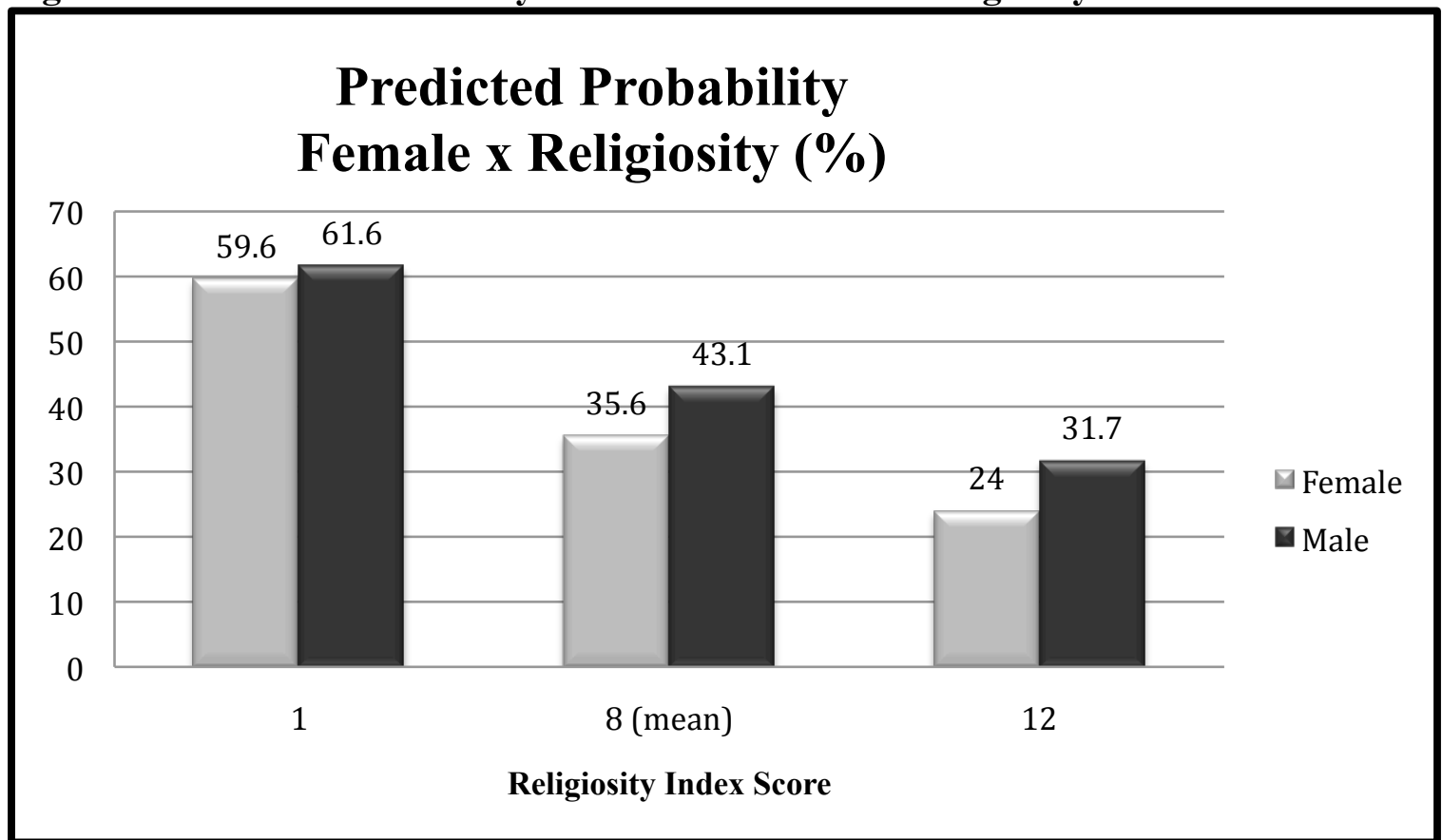

Source: National Survey on Drug Use and Health, 2011

Female $\mathrm{x}$ Never Married interaction isn't significant, the main effect for never married is significant. This finding suggests that there is something about never having married for men that makes it particularly likely for them to misuse prescription painkillers. This finding coincides with findings derived from the bivariate analyses, which strengthens the argument that men who have never been married are more likely to misuse prescription painkillers. 
The lack of significance for the majority of the interaction effects in this study may be, in fact, a result of no relationship between the variables. Or, perhaps, it is possible that the number of respondents for a particular question is too limited, resulting in insufficient data to measure significance. Finally, it is important to note that both of the significant effects were the result of interactions between gender (female) and a continuous variable (income and religiosity). Those that were not significant are all binary, or dummy variables. Continuous variables allow for more nuanced data that may, in fact, be a contributing factor to the significance of these interaction effects. 


\section{Discussion}

The purpose of this study was to examine differences and similarities in the experience of prescription painkiller misuse for men and women. More specifically, the project sought to better understand the experience of prescription painkiller misuse through a test of Travis Hirschi's social control theory and the associated social bonds of attachment (marital status), involvement (education), commitment (work status/income), and belief (religiosity/church attendance). The primary focus of the project was to determine whether the effects of these social bonds on prescription painkiller misuse are the same or different for men and women.

Results of bivariate and multivariate regressions analyses revealed that there are statistically significant gender differences in the misuse of prescription painkillers. According to these results, males are more likely than females to misuse prescription painkillers. This finding is consistent with much of the current literature (Compton et al. 2007; Greenfield et al. 2010; Back et al. 2010) and supports Hypothesis 1, which states women are less likely to misuse prescription painkillers than are men. However, there has been ongoing discourse in recent literature to suggest that women are, in fact, gaining on men in the reported incidence of drug and alcohol misuse or, in some cases misusing more than men (Kotulak 1996; Simoni-Wastila et al. 2004; Tetrault et al. 2008; Keyes et al. 2008; Malbergier et al. 2012). These oppositional findings might be explained, in part, by examining the type of study and data source used in several of these studies.

In the 2004 report by Simoni-Wastila and colleagues, data from three separate years of the National Household Survey on Drug Abuse (1991-93) were analyzed. It 
might be important to note that, in this case, the data presented had been collected at least eleven years prior to the publication of this report. The National Household Survey on Drug Abuse survey was retooled and renamed in 2002, becoming the National Survey on Drug Use and Health. Each year, prior to implementation of this annual survey, changes are often made to the format and focus of some of the questions, including the deletion of some and the addition of others. Tetrault and colleagues used data from the 2007 National Survey on Drug Use and Health. Given my firsthand knowledge of the substantial differences between the 2009 and 2011 survey instruments and their associated datasets, I feel comfortable in suggesting that the survey instrument had changed significantly between 1993 and 2007. Further, it is difficult to know exactly how each question of interest was worded, or reworded, and how the individual researchers analyzed the data they chose to include in the analyses for these publications. Therefore, conflicting results from different timeframes and data sources is always a possibility and one that must be considered in any literature review. Finally, due to the cross-sectional nature of the data in these studies, as well as my own, it is difficult to determine whether there have been changes in the misuse patterns of women that may be leading to a lessening of the previously mentioned gap between men and women in the misuse of these drugs.

In both the bivariate and multivariate analyses, when compared to being married, not being married and never having been married was significantly associated with an increase in the misuse of prescription painkillers men. This was not the case for women, which might be an indication of what some call the need for a "civilizing" influence in 
the lives of men. In other words, it might be through socialization processes such as patriarchy, where close relationships with parents are fostered for girls and freedom to explore the world is given to boys, girls are already instilled with the attachment element of social control and boys require social bonds like marriage to desist from deviant behaviors such as drug misuse. These findings are mostly consistent with current literature stating marriage, or an intimate partner relationship, is associated with a decrease in drug and alcohol abuse (Strickland \& Smith 2013; Moos \& Moos 2007; Tetrault et al. 2008) and partially support Hypothesis 2, which posits men and women who are married are less likely to misuse prescription painkillers than are men and women who are not married. However, the lack of significance in never being married and not currently being married for women should be considered, particularly in light of studies suggesting women are more likely to abuse drugs and alcohol when they are married or cohabiting because their partners are also abusing drugs and alcohol (Thompson \& Petrovic 2009; Alarid et al. 2000). That may be what is happening here. Other reasoning might include elevated drug misuse for women who are married has something to do with increased disposable income or increased free time. These explanations are suggestive of the possibility that marriage, for women, provides increased opportunity for drug misuse other than just the criminal behavior of a partner. In other words, unlike marriage for men, marriage for women becomes a facilitator for drug abuse, rather than an inhibitor.

A multivariate regression analysis shows that, for men but not women, having less than a high school diploma or some college is associated with a significant increase in the 
misuse of prescription painkillers. This finding is contrary to earlier studies in which it is suggested that for women, in particular, past-year misuse of prescription painkillers is associated with an education level between $9^{\text {th }}$ and $11^{\text {th }}$ grade (Tetrault et al. 2008). In this analysis, it was also found that having a college degree is significantly associated with a decrease in prescription painkiller misuse for men but not women. This finding is somewhat in line with studies of formal education attainment and health outcomes (Baker et al. 2011), which suggest that higher educational attainment is associated with better health outcomes, such as desistance from drug abuse and partially supports Hypothesis 4, which states men and women with higher levels of education are less likely to misuse prescription painkillers than are men and women with lower levels of education. These results show that for men but not women, having a college degree decreases the likelihood of prescription painkiller misuse, while increased use is significantly associated with having less than a high school diploma.

A multivariate analysis reveals that higher income is significantly associated with a decrease in the likelihood of misusing prescription painkillers for both men and women. This finding supports Hypothesis 5, which states men and women with higher income are less likely to misuse prescription painkillers than are men and women with lower income. Because the interaction between gender (female) and income in the analysis is also significant (AOR .94), we know that increased income has a greater negative effect on prescription painkiller misuse for women than it does for men. There is little in the existing literature that examines income and how it is specifically related to prescription painkiller misuse. For this project, income is used as a measurement of involvement, as a 
proxy for time spent at work, when examined in conjunction with work status. Hirschi's theory of social control suggests that it is the individuals' social bonds that reduce or eliminate their participation in anti-social behaviors. In other words, with the acquisition of social bonds, such as having a job, where income increases through time spent working, the individual has a higher stake in conformity. This stake makes deviating from approved norms, like participating in the misuse of prescription painkillers, a risky proposition that might lead to a loss of means or approval. For women, in particular, workforce participation and access to personal income have increased dramatically in the last 30 years. This change in the social environment might be part of what is happening here. However, as can be seen from the results of analyses regarding employment and prescription painkiller misuse, questions still persist about the mechanisms that are driving the data.

The bivariate analysis between gender and work status shows a significant positive relationship between working and prescription painkiller misuse for women, but not men. After performing a multivariate regression analysis, with interaction effects for Female $\mathrm{x}$ Working, having a job is associated with a significant increase in the odds of misusing prescription painkillers for men but not women. This finding is partial in agreement with current literature describing the relationship between gender and work, as it relates to past-year misuse of prescription painkillers (Back et al. 2010; Brady \& Randall 1999; Compton et al. 2000), which states that both men and women who work are more likely to use drugs. This association between gender and work status does not support the theoretically driven Hypothesis 6, where work is a representation of the 
involvement social bond, which states men and women who are working are less likely to misuse prescription painkillers than are men and women who are not working.

This study has attempted to look at Hirschi's element of involvement through the bond of work, with associated income. If Hirschi's theory is to hold up for this bond, having a job, with associated higher income, should decrease the odds of misusing prescription painkillers. However, when viewed separately, having a job increases the likelihood of misuse for men, but not women, while higher income decreases the likelihood of misuse for both, more so for women. One possible explanation for these results is that, through the experience of work, personal networks are enlarged, bringing about an increase in social interactions. These interactions may involve contact with colleagues and co-workers who use drugs and alcohol, which may influence participation for individuals, partially explaining the relationship between having a job and an increase in the misuse of prescription painkillers. There is still the question of why this is only true for men. This is where the element of income may play a role, particularly for women. It might be important to consider the status, or perceived prestige of a persons' job, and whether the respondent views their job as just a "job" or if they view it more as a "career." In this light, increased prestige and additional time spent at work are likely associated with increased income, with a "career" carrying more status, or a higher stake in conformity, than a "job." Therefore, the risk associated with the misuse of prescription painkillers may be too high for individuals who perceive their jobs as "careers," while those who view their job as just a "job" may not feel the risk of misusing these drugs is too high. The stress associated with having a "job" rather than a "career" may be a factor 
in the correlation between work and misuse, particularly for men. Women, because of their relatively new entrance into the workforce, may feel particularly strong about the importance of adhering to appropriate norms within the context of employment.

The results of bivariate and multivariate analyses show that level of importance of spiritual beliefs and frequency of church attendance are both significantly associated with a decrease in the misuse of prescription painkillers. This finding is consistent with literature looking at alcohol abuse and religion, which suggests that an individual's religious beliefs have a direct effect on whether or not they abuse alcohol (Kendler et al. 1997; Haber et al. 2012; Michalak et al. 2007; Patock et al. 1998), and fully supports Hypothesis 7 that posits men and women with higher levels of religiosity are less likely to misuse prescription painkillers than are men and women with lower levels of religiosity. Like marriage, church attendance is important for men in this study, while there is no significant effect for women. In other words, frequent church attendance for men leads to lowered odds of misusing prescription painkillers. This was not the case for women, which might be another indication of, the previously mentioned, need for a "civilizing" influence in the lives of men.

For clarification purposes, further analyses were performed to examine the interaction effects between all social bond variables. Initial analyses, with models including multiple variables per concept when applicable, revealed significant interactions for the following:

Never Married x Some College

Never Married x Working 
Never Married x Religiosity

Income $\mathrm{x}$ Less Than HS

Income $x$ Attend Church Frequently

Working x Attend Church Rarely

Working x Attend Church Often

Further analyses showed that many of these interactions were no longer significant as the model became more refined. For example, the Never Married x Working interaction was significant in a model containing both variables for the marriage concept (Never Married, Not Married), but when the model contained only Never Married, the interaction was no longer significant. This would suggest that the models reacting this way are extremely sensitive and may not be appropriate models to use in this project. There were several models, however, that continued to show significant interaction effects after they had been refined. Once identified, these models were stratified by gender and analyzed again (see Table 9). Table 9 shows significant interaction effects for:

Income $\mathrm{x}$ Less Than HS

Never Married x Some College

Never Married x Religiosity

It is important to note that these particular models were run independently by gender. As such, no conclusion can be made about the significance of any differences between men and women, making independent analyses and discussion necessary.

The results in Model 1 suggest that, for women with less than a high school degree, each unit increase in income decreases their odds of misusing prescription painkillers by $13 \%$. The effects of education on prescription painkiller misuse for 
women, in previous models, was not significant, while the interaction effect for Female $\mathrm{x}$ Income was significant. Model 1 in Table 9 confirms what was described in the results section of this study; increased income has a significant effect on prescription painkiller misuse for women. This finding particularly interesting, since some studies regarding the

Table 9: Logistic Regression with Social Bond Interactions

\begin{tabular}{|c|c|c|c|c|c|c|}
\hline Variable & \multicolumn{2}{|c|}{ Model 1} & \multicolumn{2}{|c|}{ Model 2} & \multicolumn{2}{|c|}{ Model 3} \\
\hline$\underline{\text { Demographics }}$ & Female & Male & Female & Male & Female & Male \\
\hline Black $^{\mathrm{a}}$ & $.55^{* *}$ & $.47 * *$ & $.67 * *$ & $.53 * *$ & $.55^{* *}$ & $.47 * *$ \\
\hline Hispanic $^{\mathrm{a}}$ & $.54^{* *}$ & $.55^{* *}$ & $.59 * *$ & $.63 * *$ & $.57 * *$ & $.59 * *$ \\
\hline Other Race ${ }^{a}$ & $.71^{* *}$ & $.59 * *$ & $.75^{* *}$ & $.61 * *$ & $.71 * *$ & $.58 * *$ \\
\hline $\begin{array}{l}\text { Age }^{\mathrm{b}} \\
\text { Social Bonds }\end{array}$ & $.90^{* *}$ & $.93^{* *}$ & $.94 * *$ & .99 & $.94 * *$ & $.99^{*}$ \\
\hline $\begin{array}{l}\text { Less Than } \mathrm{HS}^{\mathrm{c}} \\
\text { Some College }^{\mathrm{c}} \\
\text { Religiosity }\end{array}$ & $1.33^{*}$ & $1.26^{*}$ & $.86^{* *}$ & $.89 * *$ & $1.23^{*}$ & $1.25^{*}$ \\
\hline $\begin{array}{l}\text { Income } \\
\text { Never Married }^{\mathrm{d}} \\
\underline{\text { Interactions }}\end{array}$ & $.88^{* *}$ & $.91 * *$ & 1.12 & $1.33^{*}$ & $1.67 * *$ & $1.87 * *$ \\
\hline $\begin{array}{l}\text { IncomeXLTHS } \\
\text { NeverMarrXSC }\end{array}$ & $.87 *$ & .94 & & . & $.75^{*}$ & $.81^{*}$ \\
\hline NeverMarrXRel & & & 1.03 & $1.03 *$ & & \\
\hline $\begin{array}{l}-2 \text { Log likelihood } \\
\text { Number of Cases }\end{array}$ & $\begin{array}{l}17547.817 \\
20,660\end{array}$ & $\begin{array}{l}18743.099 \\
18,473\end{array}$ & $\begin{array}{l}16956.545 \\
20,220\end{array}$ & $\begin{array}{l}18120.549 \\
18,090\end{array}$ & $\begin{array}{l}17543.748 \\
20,660\end{array}$ & $\begin{array}{l}18658.982 \\
18,473\end{array}$ \\
\hline
\end{tabular}

effects of education on drug misuse suggest that having less than a high school diploma is predictive of increased odds of misuse (Tetrault et al. 2008; Baker et al. 2011). Model 2 
shows that for men who have never been married, each unit increase in religiosity is associated with a $3 \%$ increase in the likelihood of misusing prescription painkillers. This result confirms with some of the previous findings in this study, but also conflicts with others. As previously stated, men who have never been married are $69 \%$ more likely to misuse prescription painkillers, while higher levels of religiosity for both men and women are shown to have a protective effect. The results of Model 2 suggest that the protective effect of marriage for men, may be more important than levels of religiosity in relation to the misuse of prescription painkillers. Finally, Model 3 shows that for both men and women who have never been married, having some college is associated with a decrease in the odds of misusing prescription painkillers (19\% and 25\%, respectively). Keeping in mind that education show little effect for both men and women in previous models, while men who have never been married are more likely to misuse prescription painkillers, this finding suggests that, particularly for men who have never been married, the social bond associated with commitment (education) is particularly important. In this instance, Hirschi's theory appears to hold some value that was not previously identified in this project.

This test of Travis Hirschi's theory of social control as a theoretical framework for looking at gender and prescription painkiller misuse was only partially successful and seemed to be more accurate when looking at prescription painkiller misuse for men. This is not altogether surprising, since the original framework was developed using an allmale sample. Hirschi did amend his theory in later years, but the basics remained similar. In general, increased social bonds, as they were defined and operationalized in this study, 
did not necessarily lead to a decrease in the odds of misusing prescription painkillers. The inclusion of other theories, such as Differential Association Theory or General Strain Theory could be valuable to a project of this nature. These theories look specifically at peer associations and life stressors as explanations for deviance and might add clarity to this examination, where explanations are unclear or do not fit. Theories regarding social determinants of health could be important when examining the stressors associated with being unemployed or the effects of education on stress control and health outcomes. Work and education outcomes in this study, and their relationship to prescription painkiller misuse, were particularly unclear and might be better understood through this lens.

Prescription painkillers are relatively easy to get and people who misuse them often begin using them by accessing a legitimate prescription from their own physician. Most medical insurance covers these drugs and the doctors visits required to obtain them. Doctor shopping, where one person receives prescriptions from more than one doctor, is becoming a common occurrence, making recognition of the problem user difficult. Abuse and addiction rates for these drugs are increasing rapidly and the issue is complicated further by the fact that these drugs are socially acceptable and do not carry the same stigma as "hard" drugs like cocaine and heroin. For these reasons, policy examination and change has been difficult and slow. From a social, rather than individual perspective, current lawmakers might need to examine the distribution of social and economic resources in a way where drug education and drug treatment is accessible to everyone and medical insurance is not a determinant or prerequisite to that 
access. For the individual, some of the policy issues that have come to light as a result of the current project are directly related to drug treatment. Given that gender differences were found, separate treatment programs for men and women might be warranted.

Religiosity is important, particularly for women. As such, regardless of the treatment program format, a spiritual component is important and may need to be included in all cases. 


\section{Limitations}

The NSDUH dataset provides important information that can be usefully applied to the specific objectives of this project. The data are vast in scope and rich in details. The primary strengths of using this dataset are the large sample size $(58,397)$ and random sampling technique, coupled with an excellent response rate (86.98\%), allowing for good generalizability of the results. Further, beginning in 2011, changes were made to the wording of questions regarding illicit and prescription drug misuse that made it possible to examine them in connection to each other, where previous NSDUH surveys asked different questions, with different response categories regarding the misuse of prescription drug versus the use of illegal drugs, making any comparison between the two impossible. However, in addition to contributing to the strengths of this project, this dataset also presents limitations. Other than the ability to manipulate the data within the confines of SPSS, or any other data processing program, secondary data is not easily customized. By using close-ended questions, though they provide more uniform responses, certain answers or respondents feelings and attitudes may be excluded or overlooked. Further, the questions have already been asked and answers given. For this reason, the data are somewhat inflexible.

The NSDUH dataset may present certain other limitations. Primarily, these data are cross-sectional in nature, which limits the researchers' ability to examine causal relationships. For this project, in particular, causal ordering is unclear with respect to social bonds and their relationship to drug misuse. It is impossible to know which came first, or if one causes the other. In other words, we cannot determine from these data 
whether the increase in social bonds came first, leading to decreased drug misuse, or if the opposite is the case, where increased drug misuse leads to the decrease in or lack of social bonds. Further, this dataset relies on self-reports of substance abuse behavior. Self-report data can be problematic for several reasons. First, participation in the survey is voluntary and, though the literature review did not specifically indicate it, consideration must be given to the nearly $15 \%$ of the target sample population who chose not to participate. It is important to consider the reasons for non-participation. It is possible that many of the non-responders either had relationships to drug culture or may, in fact, wish to conceal a drug problem. Additionally, due to the in-person interview format of the NSDUH, results may be subject to the social desirability effect, which is the tendency of respondents to answer questions in a manner that will be viewed favorably by others. Participant recall bias can also limit the strength of self-report data.

Finally, future research might benefit from a mixed methods investigation into the differences and similarities between men and women in the misuse of prescription painkillers. While the numbers presented here are valuable and interesting, they may only show a portion of the picture. How the individual understands their own experience of the misuse of prescription painkillers might extend our knowledge of the issue and present a richer picture of an increasingly visible social problem. 


\section{Conclusion}

This research sought to further examine the effects of gender and social bonds on the experience of prescription painkiller misuse. The findings of this study suggest that, in fact, some combinations of gender and social bonds do affect prescription painkiller misuse. Travis Hirschi's social control theory can be a helpful, though not perfect, tool in our understanding of this problem. By reworking his ideas regarding adolescent males and their experience of delinquency to fit the experience of prescription painkiller misuse for adult men and women, we can see that some, but not all of the social bonds defined in this study do, in fact, decrease the likelihood of the misuse of these drugs.

In summary, this research found the characteristics that may contribute to the increased misuse of prescription painkillers are male gender, never having been married, and being employed. Characteristics that could be considered protective factors against prescription painkiller misuse are being married (for men only), having higher income, and placing importance on spiritual beliefs. No significant interaction was found between gender (female) and never having been married, having a job, attending church often, or attending church frequently. Thus, for men, never having been married and having a job are significant predictors of increased prescription painkiller misuse, while attending church often or frequently are significant predictors of decreased misuse.

Significant interactions were found between gender (female) and income and between gender (female) and religiosity. Thus, for both men and women, income and religiosity have a significant negative effect on the misuse of prescription painkillers, but the effect is greater for women. 


\section{References}

Agnew, R. 1991. "A longitudinal test of social control theory and delinquency." Journal of Research in Crime and Delinquency 28:126-156.

Alarid, L.F., V.S. Burton, and F.T. Cullen. 2000. "Gender and crime among felony offenders: Assessing the generality of social control and differential association theories." Journal of Research in Crime and Delinquency 37:171-199.

Back, S.E., R.A. Payne, A.E. Waldrop, A. Smith, S. Reeves, and K.T. Brady. 2009. "Prescription Opioid Aberrant Behaviors A Pilot Study of Sex Differences." Clinical Journal of Pain 25(6):477-484.

Back, S.E., R.L. Payne, A.N. Simpson, and K.T. Brady. 2010. "Gender and prescription opioids: findings from the National Survey on Drug Use and Health." Addict Behav 35(11):1001-7.

Back, S.E., K.M. Lawson, L.M. Singleton, and K.T. Brady. 2011. "Characteristics and correlates of men and women with prescription opioid dependence." Addict Behav 36(8):829-34.

Baker, David P., Juan Leon, Emily G. Smith, et al. 2011. "The Education Effect on Population Health: A Reassessment." Population and Development Review 37(2):307-332.

Barr, Kellie E.M., Michael P. Farrell, Grace M. Barnes and John W. Welte. 1993. "Race, Class, and Gender Differences in Substance Abuse: Evidence of MiddleClass/Underclass Polarization among Black Males.” Social Problems 40(3):314-327.

Block, J. 1984. Sex role identity and ego development. San Francisco: Jossey-Bass.

Booth, J.A., A. Farrell, and S.P. Varano. 2008. "Social control, serious delinquency, and risky behavior: A gendered analysis." Crime \& Delinquency, 54(3):423-456.

Brady, Kathleen T. and Carrie L. Randall. 1999. "Gender Differences in Substance use Disorders.” Addictive Disorders 22(2): 241-252.

Canter, R. J. 1982. "Family correlates of male and female delinquency.” Criminology 20:149-166.

Centers for Disease Control and Prevention. 2013. Vital Signs. Retrieved from http://www.cdc.gov/vital signs. 
Cernkovich, S.A. and P.C. Giordano. 1992. "School bonding, race, and delinquency." Criminology 30:261-291.

Chapple, Constance L., Julia A. McQuillan, and Terceira A. Berdahl. 2005. "Gender, social bonds, and delinquency: a comparison of boys' and girls' models." Social Science Research 34:357-383.

Chesney-Lind, M. and R.G. Shelden. 2004. Girls, delinquency, and juvenile justice. Belmont, CA: Wadsworth.

Compton Ill, W.M., L.B. Cottler, A. Abdallah, D.L Phelps, E.L. Spitznagel, and J.C. Horton. 2000. "Substance Dependence and Other Psychiatric Disorders Among Drug Dependent Subjects: Race and Gender Correlates." American Journal On Addictions 9(2):113-125.

Compton W.M., Y.F. Thomas, F.S. Stinson, et al. 2007. "Prevalence, correlates, disability, and comorbidity of DSM-IV drug abuse and dependence in the United States: results from the National Epidemiologic Survey on Alcohol and Related Conditions." Arch Gen Psychiatry 64:566-76.

Dornbusch, S.M., K.B. Erickson, J. Laird, and C.A. Wong. 2001. "The relation of family and school attachment to adolescent deviance in diverse groups and communities." Journal of Adolescent Research 16:396-422.

Erickson, K.G., R. Crosnoe, and S.M. Dornbusch. 2000. "A social process model of adolescent deviance: Combining social control and differential association perspectives." Journal of Youth and Adolescence 29:395-425.

Faupel, Charles E., Weaver, Greg S., and Jay Corzine. 2014. The Sociology of American Drug Use $3^{\text {rd }}$ Edition. New York, NY: Oxford University Press.

Freed, E.X. 1973. "Drug abuse by alcoholics: A review." International Journal of the Addictions 8:451-473.

Giordano, P. and S. Cernkovich. 1997. "Gender and antisocial behavior." Pp. 496-510 in The Handbook of Antisocial Behavior, edited by D. M. Stoff, J. Breiling, and J. Maser. NewYork: John Wiley.

Goode, Erich. 2005. Drugs in American Society 6th Edition. New York, NY: McGrawHill.

Greenfield, S.F., S.E. Back, K. Lawson, and K.T. Brady. 2010. "Substance abuse in women." Psychiatr Clin North Am 33(2):339-55. 
Haber, J.R., J.D. Grant, T. Jacob, L.B. Koenig, and A. Heath. 2012. "Alcohol milestones, risk factors, and religion/spirituality in young adult women." J Stud Alcohol Drugs 73(1):34-43.

Hall, A.J., J.E. Logan, R.L. Toblin, et al. 2008. "Patterns of abuse among unintentional pharmaceutical overdose fatalities." JAMA 300(22):2613-2620.

Hartman, Jennifer L., Michael G. Turner, Leah E. Daigle, et al. 2009. "Exploring the Gender Differences in Protective Factors: Implications for Understanding Resiliency." Int J Offender Ther Comp Criminol 53(3): 249-277.

Heimer, K. and De Coster, S. 1999. "The gendering of violent delinquency." Criminology 37:277-317.

Hirschi, T. 1969. Causes of delinquency. Berkeley: University of California Press.

Huebner, A.J. and S.C. Betts. 2002. "Exploring the utility of social control theory for youth development." Youth and Society 34:123-145.

Kendler K.S., C.O. Gardner and C.A. Prescott. 1997. "Religion, psychopathology, and substance use and abuse: a multimeasure, genetic-epidemiologic study." Am J Psychiatry 154(3):322-329.

Keyes, Katherine M., Bridget F. Grant, Deborah S. Hasin. 2008. "Evidence for a closing gender gap in alcohol use, abuse, and dependence in the United States population." Drug and Alcohol Dependence 93:21-29.

Kotulak, Ronald. 1996. "Women Narrow Gender Gap In Drug, Alcohol Abuse.” Chicago Tribune, June 6.

Laub, J.H. and R.J. Sampson. 2003. Shared beginnings, divergent lives: Delinquent boys to age 70. Cambridge, MA: Harvard University Press.

Laundra, K.H., G. Kiger, and S.J. Bahr. 2002. “A social development model of serious delinquency: Examining gender differences." Journal of Primary Prevention, 22:389407.

Liu, X. and H.B. Kaplan. 1999. "Explaining the gender difference in adolescent delinquent behavior: A longitudinal test of mediating mechanisms." Criminology, 37:195-215. 
Lofwall, Michelle R., Paul A. Nuzzo, and Sharon L. Walsh. 2012. "Effects of cold pressor pain on the abuse liability of intranasal oxycodone in male and female prescription opioid abusers." Drug and Alcohol Dependence 123(1-3): 229-238.

Malbergier, André, Luciana Roberta Donola Cardoso, Ricardo Abrantes do Amaral, and Verena Castellani Vitor Santos. 2012. "Gender parity and drug use: are girls catching up with boys?" Rev Bras Psiquiatr 34:16-23.

McCabe, S.E., J.A. Cranford, and B.T. West. 2008. "Trends in prescription drug abuse and dependence, co-occurrence with other substance use disorders, and treatment utilization: results from two national surveys." Addict Behav 33(10):1297-1305.

McLellan, A. Thomas, Arthur I. Alterman, David S. Metzger, Grant R. Grissom, George E. Woody, Lester Luborsky, and Charles P. O’Brien. 1994. "Similarity of Outcome Predictors Across Opiate, Cocaine, and Alcohol Treatments: Role of Treatment Services." Journal of Consulting and Clinical Psychology 62(6):1141-1158.

McNelis, Angela. 2012. "Indiana State Nurses Assistance Program: Identifying Gender Differences in Substance Use Disorders." Perspectives In Psychiatric Care 48(1):4146.

Michalak L., K. Trocki, and J. Bond. 2007. "Religion and alcohol in the U.S. National Alcohol Survey: how important is religion for abstention and drinking." Drug Alcohol Depend 87:268-280.

Miller, M.H., F. Esbensen, and A. Freng. 1999. "Parental attachment, parental supervision and adolescent deviance in intact and non-intact families." Journal of Crime and Justice 22:1-29.

Moos, Rudolf H. and Bernice S. Moos. 2007. "Protective resources and long-term recovery from alcohol use disorders." Drug and Alcohol Dependence 86:46-54.

Patock-Peckham, J.A., G.T Hutchinson, J. Cheong, and C.T. Nagoshi. 1998. "Effect of religion and religiosity on alcohol use in a college student sample." Drug Alcohol Depend 49:81-88.

Sampson, Robert J. and John H. Laub. 1993. Crime in the Making: Pathways and Turning Points through Life. Cambridge, MA: Harvard University Press.

Simoni-Wastila L., G. Ritter, and G. Strickler. 2004. "Gender and other factors associated with the nonmedical use of abusable prescription drugs." Substance Use \& Misuse 39(1):1-23. 
Skinner, Harvey A. 1982. “The Drug Abuse Screening Test.” Addictive Behaviors 1:363371.

Smith, D. and R. Paternoster. 1987. "The gender gap in theories of deviance: Issues and evidence." Journal of Research in Crime and Delinquency 24:140-172.

Strickland, Justin C. and Mark A. Smith. 2014. "The Effects of Social Contact on Drug Use: Behavioral Mechanisms Controlling Drug Intake." Experimental and Clinical Psychopharmacology 22(1):23-34.

Substance Abuse and Mental Health Services Administration (SAMHSA). 2012. Center for Behavioral Health Statistics and Quality, National Survey on Drug Use and Health, 2007, 2008, 2010 and 2011.

Tetrault J.M., R. A. Desai, W.C. Becker, et al. 2008. "Gender and non-medical use of prescription opioids: results from a national US survey." Addiction 103:258-68.

Thompson, Melissa and Milena Petrovic. 2009. "Gendered Transitions: Within-Person Changes in Employment, Family, and Illicit Drug Use." Journal of Research in Crime and Delinquency 46(3):377-408.

Thornberry, T. P. 2006. "Membership in youth gangs and in serious and violent offending." Pp. 224-232 in The Modern Gang Reader, edited by A. Egley Jr., C. L. Maxson, J. Miller, and M. W. Klein. Los Angeles: Roxbury.

Thorne, B. (1994). Gender at play: Girls and boys in school. New Brunswick, NJ: Rutgers University Press.

Vogt Yuan, Anastasia S. 2010. "Black-White Differences in Aging Out of Substance Use and Abuse." Sociological Spectrum 30(1):3-31.

Wilson, William J. 1978. "The declining significance of race." Society, 15(5):11-.

Worthen, Meredith G.F. 2011. "Gender differences in parent-child bonding: implications for understanding the gender gap in delinquency." Journal of Crime and Justice 34(1):3-23.

Wright, J.P., F.T. Cullen, and J.T. Miller. 2001. "Family social capital and delinquent involvement." Journal of Criminal Justice 29:1-9. 